\title{
Recall and Response: Relationship Adjustments to Adverse Information Shocks
}

\author{
by
}

\author{
Emek Basker \\ U.S. Census Bureau \\ Fariha Kamal \\ U.S. Census Bureau
}

\section{CES 20-13 March, 2020}

The research program of the Center for Economic Studies (CES) produces a wide range of economic analyses to improve the statistical programs of the U.S. Census Bureau. Many of these analyses take the form of CES research papers. The papers have not undergone the review accorded Census Bureau publications and no endorsement should be inferred. Any opinions and conclusions expressed herein are those of the author(s) and do not necessarily represent the views of the U.S. Census Bureau. All results have been reviewed to ensure that no confidential information is disclosed. Republication in whole or part must be cleared with the authors.

To obtain information about the series, see www.census.gov/ces or contact Christopher Goetz, Editor, Discussion Papers, U.S. Census Bureau, Center for Economic Studies 5K038E, 4600 Silver Hill Road, Washington, DC 20233, CES.Working.Papers@census.gov. To subscribe to the series, please click here. 


\begin{abstract}
How resilient are buyer-supplier relationships to new information about product defects? We construct a novel dataset of U.S. consumer product recalls sourced from foreign suppliers between 1995 and 2013. Using an event-study approach, we find that, compared to control relationships, buyers that experience recalls temporarily reduce their probability of trading with the suppliers of the recalled products by 25\%. A milder decrease persists, accompanied by increased reliance on other foreign suppliers. Buyers that are affliated with their suppliers decrease trade several quarters earlier than unaffiliated buyers, consistent with decisionmaking and information flowing faster within than across firm boundaries.
\end{abstract}

Keyword: Buyer-supplier relationships; information flows; firm boundary; recalls

JEL Classification: L14, L15, F14, F23

\footnotetext{
*Comments welcome. Author contact: emek.m.basker@census.gov and fariha.kamal@census.gov.

Any opinions and conclusions expressed herein are those of the authors and do not necessarily represent the views of the U.S. Census Bureau. The Census Bureau's Disclosure Review Board and Disclosure Avoidance Officers have reviewed this data product for unauthorized disclosure of confidential information and have approved the disclosure avoidance practices applied to this release (DRB Approval Numbers: DRB-B0114-CDAR-20180807, DRB-B0075CED-20190916, CBDRB-FY20-171, and CBDRB-FY20-CES008-001). We thank Tanya Topka for providing background on the Consumer Product Safety Commission and the consumer-product recall process, James Boohaker for invaluable and painstaking research assistance, Enghin Atalay, Saku Aura, Benjamin Bridgman, Silke Forbes, Richard Friberg, Cheryl Grim, Tom Holmes, Mallick Hossain, J. Bradford Jensen, Oksana Loginova, Alessia Lo Turco, Pamela Medina-Quispe, Bruno Merlevede, Jagadeesh Sivadasan, Pham Hoang Van, Jon Williams, Yingyan Zhao, Nikolas Zolas, and seminar and conference participants at the U.S. Census Bureau, American University, University of Massachusetts, 2018 FSRDC, 2018 SEA, 2019 MATW, 2019 WCTW, 2019 CAED, 2019 IIOC, 2019 SIOE, 2019 BGSE "Firms in the Global Economy," and 2019 SETC for helpful comments and discussions.
} 


\section{Introduction}

Relationships between individual buyers and suppliers are the building blocks to functioning markets. Understanding how relationships adjust in response to new information is fundamental to understanding how markets function, both domestically and internationally. In this paper, we use a quasi-random experiment setting to explore the margins of adjustment for buyer-supplier relationships that experience negative information shocks. Specifically, we investigate the impacts of consumer-product recalls for health or safety reasons on the relationships between U.S. firms and their foreign suppliers.

Consumer-product recalls are specific to a buyer (retailer or distributor), supplier (manufacturer), and product, and hence serve to identify information shocks to buyer-supplier relationships. The recall process begins as a result of internal quality-control checks or complaints submitted directly to the seller or government by consumers, competitors, and health officials. A firm whose product is under investigation receives an official notice of the investigation and is apprised of the conclusions before the public recall announcement. The process conveys information to a distributor or retailer about the quality of the production process at the supplying firm; it is this shock that may prompt the buyer to evaluate its relationship with the supplier both at the extensive (stay or switch) and intensive (increase or decrease shipments) margins.

To study these margins of response to the shocks, we construct a novel dataset of the universe of U.S. consumer-product recalls sourced from foreign suppliers between 1995 and 2013 from Consumer Product Safety Commission (CPSC) public notices. We identify the imported shipments most likely associated with a recall in confidential customs transaction records linked to firm identifiers by the U.S. Census Bureau, using information about the U.S. buyer, foreign supplier, product, and shipment date. We use the customs transaction data to identify control relationships: buyer-supplier pairs with similar trade patterns, trading similar products, around the same time as the treated pairs. We exclude control pairs that may have been indirectly affected by the recall, such as buyers that ever traded with the 
treated supplier, suppliers that ever traded with the treated buyer, and pairs that traded close substitutes of the recalled product. Once we identify buyer-supplier relationships impacted by recalls, along with appropriate control relationships, we use the high frequency of the customs records to trace the precise timing of adjustments firms make both in anticipation of and immediately following the recall announcement. Tracing the firms' transactions in the period before and after the recall announcement enables us to identify the timing of the information shock and infer which parties knew about the product defect before it was announced and how long before, shedding light on how information is transmitted in supply networks. ${ }^{1}$

We implement an event-study approach that treats recalls as quasi-random experiments. Although the types of product defects that trigger recalls may be precipitated by the firms' choices and actions, recalls are both rare and, empirically, hard to predict. Nevertheless, our empirical specifications include buyer-supplier fixed effects that control for the possibility that some buyer-supplier pairs have a higher probability of experiencing a recall.

We begin by establishing three key results that are consistent with our view of recalls as quasi-random. First, compared to control relationships, relationships shocked by a product defect experience a 12-percentage point decrease in the probability of trade that persists for two quarters, followed by a partial recovery. Second, this sharp drop - equivalent to a decline in the probability of trade by about $25 \%$ - begins, on average, two quarters before the recall is publicly announced, consistent with the announcement being a symptom, and not the cause, of the disruption. Third, trade does not fully recover even two years after the recall announcement. Combined, these findings suggest that the product recall - or, rather, the information shock the precedes it - is unanticipated by the trading firms.

Product recalls have both direct and indirect effects on trading relationships. The decline

\footnotetext{
${ }^{1}$ Our interest in the shock to firms' information sets distinguishes our paper from papers that analyze the impact of recalls through the lens of consumer response, such as Freedman, Kearney, and Lederman (2012) and Zhong (2018).
} 
in the probability of trade is not limited to the recalled product, but impacts all products sourced from the same foreign supplier. The probability of trading any other products with the implicated supplier drops by five percentage points, or about 10\%. Even conditional on continued trading, the value of trade falls in relationships that experience a recall, although this effect is short lived. In addition, buyers increase their purchases from alternate suppliers by about $10 \%$.

Finally, the decline in the probability of trade with the supplier of the recalled product occurs earlier when the buyer is affiliated with its suppliers. ${ }^{2}$ The difference in the timing of the impact by the buyer and supplier's affiliation status is consistent with firm boundaries impeding information flows surrounding the product defect. Buyers that are affiliated with the recalled products' suppliers experience a sharp reduction in the likelihood of trade almost a year prior to the public announcement. This result is consistent with information transmissions occurring faster within than across firm boundaries. Affiliated buyers have the opportunity to learn about problems in the production process and make adjustment early as a result of a common management, consistent with prior research that finds the transfer of intangible inputs, such as management oversight, within firms to be a key reason for affiliation (Atalay, Hortaçsu, and Syverson, 2014; Ramondo, Rappoport, and Ruhl, 2016).

Our results highlight how the nature of a shock affects its propagation in production networks. Studies seeking evidence of the propagation of shocks in production networks have typically studied large-scale shocks, such as natural disasters, that impact the operations of either all the buyers or the sellers within a defined geographic area. Our work differs from these prior papers on an important dimension: we study the impacts of a relationship-specific shock in the presence of alternate sourcing options.

Barrot and Sauvagnat (2016, Figure IV), for example, find that a firm's sales growth falls by $2-3$ percentage points when a natural disaster affects a major supplier to that firm.

\footnotetext{
${ }^{2}$ Affiliated relationships are those in which one firm owns a stake of $6 \%$ or more in the other; we use this variable to proxy for the presence of a firm boundary between the buyer and the supplier.
} 
In that case, the decline takes 3-4 quarters to materialize. In contrast, we find that buyers respond almost immediately to a relationship-specific shock, increasing purchases from other suppliers within a quarter of learning about the product defect. One possible explanation for the difference between our findings is that, unlike Barrot and Sauvagnat (2016), we have direct information about trade between the two firms; sales may take a while to be affected if firms maintain sufficient inventories to ride out temporary trade disruptions. Boehm, Flaaen, and Pandalai-Nayar (2019) use data from the March 2011 Tohoku earthquake that disrupted production of Japanese multinational parent firms supplying key inputs to their U.S. affiliates, and find that, on average, the U.S. affiliates' output fell by almost the same magnitude as the reduction in imported inputs. Imports by U.S. affiliates fells immediately - in the month following the earthquake - but fully recovered after six months. In contrast, our findings that affiliated relationships do not fully recover in terms of trading probabilities even two years after the recall announcement suggests that the adjustment duration depends on both the type of the shock the relationship experiences and the availability of alternate suppliers.

The focus on recalls affecting relationships of U.S. buyers and their foreign suppliers allows us to analyze how quickly relationships adjust in global production networks. This is especially relevant in an era where goods production is increasingly fragmented, both within and across national borders (see, e.g., Holmes, 1999; Fort, 2017; Antrás, Fort, and Tintlenot, 2017). Our findings suggest that U.S. buyers are able to quickly adjust to relationship-specific shocks even when the supplier is located in a foreign country.

The rest of the paper is organized as follows. Section 2 provides background on the recall process. Section 3 describes our data sources and our procedure for merging them, identifying recalled shipments and affected relationships, and identifying appropriate control shipments and relationships. We lay out the empirical approach and results in Section 4. Section 5 concludes. 


\section{Product Recalls in the United States}

Product recalls represent a breakdown in the production process, due to design, communication, or manufacturing errors (Lyles, Flynn, and Frohlich, 2008). Our study uses information on consumer-product recalls administered by the Consumer Product Safety Commission, established by the the 1972 Consumer Product Safety Act. The CPSC promotes the safety of over 15,000 consumer goods such as toys, furniture, consumer electronics, and all-terrain vehicles. ${ }^{3}$ Product recalls are conducted as part of CPSC's goal of addressing unreasonable risks of injury to consumers. The main objectives of a recall are identifying and locating all defective products, removing them from the distribution chain and possession of consumers, and communicating information to the public about the defect, hazard, and corrective action (U.S. Consumer Product Safety Commission Office of Compliance \& Field Operations, 2012). Figure 1 shows the number of recall announcements of imported products, by year, between 1995 and 2013. The peak in 2007 represents the widespread recall of toys manufactured in China.

There are at least four types of costs to firms associated with product failures. First, there is the cost of the investigation into the cause of the problem, which may disrupt production schedules. Second, there is the cost of issuing refunds or replacement products or providing repairs. Third, there is the cost of making changes in the design, production process, sourcing, or other failures. Finally, there may be a cost of consumer goodwill, which can last for a long time (Kumar and Schmitz, 2011; Zhong, 2018). For all these reasons, companies have an incentive to minimize their risk of product failures.

Product recalls are a process that culminates with the posting of a public notice in the form of a press release: the recall announcement. The process begins when a complaint is filed with CPSC or the company. The complaint may originate with a consumer, a competitor, or a professional such as a healthcare provider who believes the product may have caused

\footnotetext{
${ }^{3}$ The main products excluded from CPSC's jurisdiction are automobiles, guns, food, cosmetics, and drugs.
} 
or poses harm. The complaint may also come from the manufacturer, importer, distributor, or seller of the product if the firm discovers a defect or is notified of one by a customer. Companies that have been notified of a possible hazard related to their products have a legal duty to report this information to the CPSC within 24 hours (U.S. Consumer Product Safety Commission Office of Compliance \& Field Operations, 2012, pp. 6-8). CPSC then launches an investigation to identify the product hazard using four main criteria: pattern of defect, number of defective products in commerce, severity of risk, and likelihood of injury. In many cases, the investigation concludes that no corrective action is needed, and the case is closed. If the Commission deems that a product poses a risk to consumers, it initiates a recall by sending a letter to the company. The company must then implement a corrective-action plan, which may entail ascertaining the nature and scope of the defect, discontinuing production, ordering replacements, halting retail sales, devising a communications and consumer response plan, and installing upgrades to quality-control systems to avoid future hazards.

The situation depicted in Figure 2 is one in which the product is no longer sold to consumers when the firm becomes aware of a problem in production. If the product is still available for sale at the time of the information shock, the firm may discontinue sales then, or wait for the results of the investigation. Only once a corrective-action plan is in place is the public notified of the recall.

This complex process implies that by the time the press release is made available to the public - the product is officially recalled - the buyer, and likely its supplier, already know what to expect, and have had the opportunity to prepare a response to the recall. Unfortunately, we do not observe the exact date of the shock to the firms - i.e., the date when they first discover, or begin to address, the product or process defect. Instead, we have the date of the recall announcement; the dates of the shipments we have associated with the recall announcement; and, in most cases, also the dates of production and/or sale, as reported in the recall announcement. On average, in our sample of recalls, sale to consumers begins within a couple of weeks of the earliest production date ( $p_{1}$ to $s_{1}$ in Figure 2$)$, and 
continues for several months after the last production date $\left(p_{2}\right.$ to $\left.s_{2}\right)$. On average, a few months separate the last date of sale from the date of the recall announcement $\left(s_{2}\right.$ to $r$ ). However, the lag between last sale and recall announcement can range from zero (sales cease only with recall announcement) to several years. ${ }^{4}$

Because we cannot identify the exact date when the buying firm first becomes aware of an issue we treat the recall announcement itself as an outcome of the unobserved negative shock to the buyer-supplier-product relationship.

\section{Data}

\subsection{Data Sources}

Our empirical analysis relies on three sources of administrative data: import transactions data from the Longitudinal Firm Trade Transactions Database (LFTTD), recall data from CPSC, and business name from the Business Register (BR).

\subsubsection{Longitudinal Firm Trade Transactions Database and Business Register}

The LFTTD contains transaction-level detail on the universe of imported shipments valued over US\$2,000 of merchandise goods into the U.S. starting in 1992. These data originate with U.S. Customs and Border Protection and are augmented with a firm identifier by the U.S. Census Bureau. There are seven variables key to our analyses: an identifier for the buyer (U.S. firm), an identifier for the manufacturer or supplier (foreign firm), the date of

\footnotetext{
${ }^{4}$ In the later years of our sample, an increasing share of recalls were handled under the CPSC's "FastTrack" program, which allows the recall to take place without a full investigation; such recalls are typically completed within 40 business days. However, recall notices did not begin specifying the "Fast-Track" status of a recall until 2013. Therefore, for effectively all of our sample, we cannot distinguish "Fast-Track" recalls. Certain products require complex planning, for example in the case of batteries, where disposal of the item can itself be hazardous. Very large recalls can also require extra planning. In other cases, products may cross regulatory jurisdictions. For instance, if an injury is caused by the straw in a drinking cup then both the CPSC and the Food and Drug Administration have jurisdiction over the case, and the agencies must agree on the details of the recall.
} 
the transaction, the product traded (HS10 designation), the shipment's country of origin, the dollar value of the shipment, and whether or not the supplier and buyer are affiliated. Affiliated relationships are those in which one firm owns a stake of at least $6 \%$ in the other. It is an indicator variable; we do not observe the actual equity shares. ${ }^{5}$

The supplier's identity is encoded in an alphanumeric variable, called the manufacturer identifier (MID), that includes a two-digit country code, the first three letters of the first word and the first three letters of the second word in the supplier's name, the numeric portion of the street address, and the first three letters of the city name. ${ }^{6}$ We remove the numeric and city portion of the variable to create a supplier-country pair identifying the supplier. Within a country, the abbreviated supplier name enables us to link shipments to the recall data.

The BR is a continuously updated database of business establishments operating in the U.S. and includes business names at the establishment level and a unique firm identifier indicating common ownership of a given set of establishments (DeSalvo, Limehouse, and Klimek, 2016). We match the U.S. buyer names listed in the publicly available productrecall announcements to the universe of business names in the BR to assign a firm identifier to a recall announcement, which can then be linked to the LFTTD.

\subsubsection{Recall Data}

The CPSC data used in this study includes all consumer-product recalls from 1995 to 2013. The dataset includes over 5,000 recall notices, of which approximately 3,000 are associated with imported products.

Most recall notices include only a single product, but some include several products that may or may not share similar characteristics. The vast majority $-90 \%$ - of the notices

\footnotetext{
${ }^{5}$ The ownership status between trading parties is denoted by item 32.C in Form-7501.

${ }^{6}$ For example, Basker-Kamal Enterprises, 4600 Silver Hill Road, Washington, DC 20233, USA, would have an MID: US-BASKAM-4600-WAS. More details on the manufacturer identification code is available in Kamal and Monarch (2018).
} 
are dated after $2001 .^{7}$ We focus on creating consistent variables to enable linking the recall data to the LFTTD. Figure 3 shows an example of the official press releases prepared by CPSC in conjunction with U.S. firms, which form the basis for our analysis. ${ }^{8}$ We extract, from each press release, the date of the recall announcement, the name(s) of the U.S. buyers (the firms importing, distributing, or retailing the product), the product type and detailed product description, the name(s) and locations of the foreign suppliers (manufacturers or intermediaries), and the dates or date ranges of manufacture, import, and sale. Not all of these variables are available for every recall. We exclude recalls with missing key information, such as the name of the U.S. buyer. We use the product name and detailed description to assign each recall one or more HS codes.

To get a sense of how prevalent recall events are across broad product categories, we calculate the percentage share of import shipments over the 1995-2013 period that are associated with a recall. ${ }^{9}$ Table 1 displays these percentage shares for the top nine HS2 categories in the recall data, which collectively represent more than three quarters of the recalls of imported products. Recalls are extremely rare events: among all product categories, toys are most likely to be recalled, with a probability of about $0.01 \%$.

\subsection{Treated and Control Shipments}

We link the product-recall data, which contain the U.S. buyer name, foreign supplier name, country of origin, product code assigned by us based on the product description, and a set of dates (for the production, import, sales, and the recall announcement), to the LFTTD in order to identify the shipment associated with the recall. We start by linking the importer

\footnotetext{
${ }^{7}$ The CPSC occasionally re-issues press releases, e.g., when the injuries are severe or there are changes to the remedy offered. Our dataset excludes such updated releases.

${ }^{8}$ This example is given for illustrative purposes only. The recall was announced in 2017, four years after the end of our sample period.

${ }^{9} \mathrm{~A}$ product recall may be associated with multiple products. In these cases, we count a recall multiple times across product categories. Our calculation assumes that a single recall-HS2 is associated with a single import shipment.
} 
names obtained from the recall announcements to business names at the establishment level to assign one or more possible firm identifiers to each shipment, and narrow down the possible matches using information about the product, country of origin, supplier name, and the dates listed in the recall announcement. The linking process is described in more detail in Appendix A.1.

We find one or more shipments that match the available information on the recall notice for approximately three quarters of the notices. ${ }^{10}$ These are our treated shipments. The treated shipments are dominated by imports of furniture, toys, electrical machinery, clothing, and plastic products, sourced primarily from China, Hong Kong, Taiwan, Canada, Mexico, and Japan.

To select control shipments for each treated shipment, we start by identifying shipments that share a country of origin, a broad product classification (HS4), and a similar time period (within 90 days of the recalled shipment). We refine the control set by matching the treatment's pre-recall firm- and relationship-level characteristics including the firm's total shipment value over a three-year period and the firm's value of shipments from the supplier of the treated (control) shipment over the same period. Recalled shipments for which we cannot assign controls are dropped from our analysis. The details of the control-group selection are discussed in Appendix A.2.

We take several steps to ensure that our control observations are themselves not impacted by the recall either directly or indirectly. The product recalls we identify are generally specific to the relationship and product, unlike recalls that are industry-wide (e.g., recalls of airbags by Takata that impacted many automobile manufactures; see Consumer Reports, 2018), so importers and exporters of similar products should not be directly impacted by a recall. ${ }^{11}$ First, although the control shipments share an HS4 product classification with the

\footnotetext{
${ }^{10}$ Unmatched notices are missing the names of the U.S. buyers.

${ }^{11}$ Freedman, Kearney, and Lederman (2012) and Zhong (2018) argue that recalls have secondary effects on competitors, because consumers may not know the details of the recall. To the extent that this is the case, our results provide an under-estimate of the full effect. The toy recalls in 2007 and 2008 impacted the
} 
treated shipments, we exclude any controls that share an HS6 product classification with the treatment. Second, we exclude from our set of control buyers any buyer that had ever traded with the treated supplier; and likewise exclude any control supplier that had ever traded with the treated buyer. Finally, we exclude from the controls firms involved in any other recalls.

We also address this concern with a second identification strategy. Instead of using shipments to and from different firms around the same time period as controls, in the alternative control group we select a control shipment purchased by the same U.S. buyer (from a different supplier, but the same country) of the same broad product classification (HS2) two years $( \pm 90$ days $)$ prior to the recalled shipment. This control group has an important advantage, as well as some disadvantages, over the main control group. First and foremost, by construction, the control relationship - two years prior to the recall - cannot have been impacted, directly or indirectly, by the recall. However, the set of buyers for which we find a control shipment meeting these criteria is relatively small, limiting our power, particularly for estimating heterogeneous treatment effects. This sample is also selected to skew larger and older than the main sample because a firm has to have similar shipments two years apart to be included. We use this smaller sample using same-firm controls for a robustness check.

Finally, we select a third set of control observations to match the characteristics of the supplier, rather than the buyer. These are selected using the same procedure as the one we use to match on the characteristics of the buyer. Both the own-firm and the supplier controls are described in more detail in Appendix A.3.

\subsection{Analysis Sample}

To study the impact of product recalls, we follow the trading history of the buyers and suppliers associated with each treated and control shipment. We divide the 720 days before

largest U.S. toy companies and, of all the recall events used in our analysis, are the most vulnerable to this critique. All our results are robust to excluding toy recalls. 
and after each recall into sixteen 90-day intervals. We use this constructed quarterly dataset to study the evolution of trading relationships at a relatively high-frequency, granular level. For each treated and control pair, consisting of a buyer $b$ and a supplier $s$, in each quarter $t$, we determine whether, and how much, the pair traded the recalled product $p$ as well as other products; and whether, and how much, the buyer traded with other foreign suppliers. We restrict all U.S. buyers in our sample to those with at least one shipment in every quarter (not necessarily with each other), which removes any exiters from our sample. This allows us to examine trading behavior conditional on the firm continuing to exist and trade. ${ }^{12}$ On average, a treated shipment is linked to seven control shipments. The analysis samples include 480 treated and 2,800 control buyer firms.

Table 2 provides summary statistics on the treated and control buyers and suppliers using data from quarters -8 through -5 relative to the recall announcement. ${ }^{13}$ The first panel shows the average probability, across the four quarters, of the buyer purchasing a shipment with the same HS6 as the recalled product from the implicated supplier. For the controls, the table shows the average quarterly probability of the buyer purchasing a shipment with the same HS6 as the control shipment from the supplier of the control shipment. The means of this variable are about $46 \%$ for the treatment group and $45 \%$ in the control group. In the second panel, we calculate the quarterly probability of the buyer importing one or more shipments of some other product (different HS6) from the same buyer; this probability is about $57 \%$ for treated firms and $58 \%$ for control firms.

For buyers that experience a recall, the average quarterly value of imports purchased from the implicated supplier is about $\$ 6$ million (2015 dollars) and about $\$ 117$ million purchased from all other suppliers. For buyers in the control group, the average value of imports

\footnotetext{
${ }^{12}$ In practice, this removes a very small number of firms from our sample.

${ }^{13}$ Guided by conversations with CPSC officials, our understanding is that the average recall process (including investigation and remedial action) lasts between several weeks and several months, but typically less than a year. We therefore consider the second year prior to the public announcement to be a period most likely uncontaminated by the recall process.
} 
purchased from the supplier of the recalled shipment is about $\$ 15$ million, with about $\$ 66$ million purchased from all other suppliers. The average traded values are influenced by the presence of very large importers in both samples. Therefore, we also report the median traded values; these are similar across the treated and control groups for both variables. We also report the value of shipments imported from other suppliers, i.e., suppliers other than the supplier of the recalled (control) shipment.

Throughout the analysis, we match affiliated buyer-supplier treatment pairs with affiliated control pairs, and unaffiliated treated pairs with unaffiliated control pairs. We also separately analyze the response of affiliated and unaffiliated buyer-supplier pairs. Table 3 shows summary statistics on the treated and control buyers and suppliers separately by their affiliation status. For affiliated pairs that experienced a recall, the average quarterly probability of purchasing the recalled product in the pre-recall period is about $54 \%$; the equivalent

for the control group is $49 \%$. For unaffiliated pairs, these probabilities are about $45 \%$ and $44 \%$, respectively.

The summary statistics reveal similar distributions of key variables in the treatment and control groups two years prior to the recall announcement. Our event-study results in the next section also demonstrate that, for most outcomes, the treated and control group responses exhibit parallel trends in the pre-shock period.

\section{Results}

\subsection{Regression Specification}

We begin by estimating the following regression equation using data from the four-year interval surrounding the recall announcement:

$$
\text { Import }_{b s p t}=\gamma_{b s p}+\pi_{t} \text { Quarter }_{t}+\beta_{t} \text { Treated }_{b s p} \text { Quarter }_{t}+\varepsilon_{b s p t}
$$


where Import $_{b s p t}$ is a measure of imports of buyer $b$ having one or more shipments of product $p$ (defined at the HS6 classification level) from supplier $s$ in quarter $t$. In most regressions, we use an indicator for any imports to study the extensive margin of adjustment; in a few models we use the log of import value, which is defined only for active relationships in any given quarter, to study the intensive margin. The relationship-specific fixed effect, $\gamma_{b s p}$, captures unobservable effects of the buyer-supplier-product in the window of time surrounding the recall. ${ }^{14}$ Quarter $_{t}$ is a quarter fixed effect, defined relative to the date of the recall announcement. Treated $_{b s p}$ is a time-invariant indicator that equals one if buyer $b$ experienced a recall of product $p$ purchased from supplier $s$. On its own, Treated ${ }_{b s p}$ is perfectly collinear with the relationship fixed effects, but interacted with the quarter fixed effects it allows us to identify the differential trade patterns for treated and control relationships. Standard errors are clustered by recall, allowing for arbitrary autocorrelation in the error terms for a given treatment or control observation, and also for arbitrary correlation across treatment and control observations for the same recall. We estimate similar equations using other outcome variables, such as whether the buyer imported other products from the same supplier, or whether the supplier sold the same product to other buyers.

The vector of parameter estimates $\boldsymbol{\beta}$ describes how the trading relationship evolves before and after the recall announcement. As noted earlier, the information shock to the buyer-supplier relationship predates the announcement, possibly by months. We view both the recall announcement and the buyer-supplier relationship in the months before as well as after the announcement as outcomes of this unobserved shock. The designation $t=0$, for the quarter immediately following the announcement, is therefore a convenient normalization rather than an indication of the date of the shock.

A causal interpretation of the coefficients requires that the assignment of treatment and control buyer-supplier pairs be independent of the error term. In our context, the

\footnotetext{
${ }^{14}$ If a single buyer-supplier-product tuple experiences more than one recall, we allow separate fixed effects associated with the observations surrounding reach recall.
} 
assignment of treatment - pairs that experience a recall - may not be completely random. Some products, countries, or firms may have higher propensity than others to experience recalls, and may also have other observed or unobserved differences. We carefully select our control group to include broadly similar buyers and suppliers, with broadly similar trading relationships (same affiliated status, similar overall imports over a three-year period, and similar importance of the traded product in their portfolio). Nonetheless, treated and control firms may still differ on important dimensions, some of which may be unobservable. In Appendix B we show that recalls are largely unpredictable. We also include buyersupplier fixed effects in all our specifications and examine the pre-recall relationship over eight quarters. Our key identifying assumption is that recalls are uncorrelated with timevarying factors that directly influence trade.

\subsection{Relationship-Level Effects}

Figure 4 shows the coefficient vector $\boldsymbol{\beta}$, along with $95 \%$ confidence intervals, from Equation (1). The dependent variable is $\mathbb{I}\left(\operatorname{Imports}_{b s p t}>0\right)$, an indicator that equals 1 iff buyer $b$ purchases recalled product $p$ from supplier $s$ in quarter $t$. To interpret the sixteen coefficients, note that the recall announcement occurs just before quarter 0 , and that $\beta_{-8}$ is normalized to be zero. Therefore, for $t>-8$, the coefficient $\beta_{t}$, on the interaction of treatment and quarter $t$, represents the difference between the probability that a treated buyer purchases the recalled product from the treated supplier, and the probability that a control buyer purchases the HS6 product of the control shipment from the supplier of the control shipment, in quarter $t$, relative to that difference eight quarters before the recall announcement.

The relatively flat coefficients for $t=-8,-7, \ldots,-3$ indicate that the treatment and control pairs' probabilities of trade follow parallel trends for over a year before diverging. The divergence is abrupt and large: two quarters before the recall announcement, the probability that the U.S. firm trades with its foreign supplier falls by approximately 12 percentage points relative to the control pair's probability of trade. From Table 2, the probability that a given 
buyer-supplier pair in our sample trades in any particular quarter is about $45 \%$; the $12 \mathrm{pp}$ decline therefore represents an economically significant drop of about $25 \%$ in the probability of trade. The probability of trade remains $12 \mathrm{pp}$ below that of the control in the quarter before the public announcement, then rises, but does not recover to the same level as a year before the shock. Two years after the recall announcement, the treated pairs are still less likely to trade than the control pairs.

The most compelling explanation for the decline in the probability of trade prior to the public announcement is that the U.S. buyer has private information about the product defect and impending recall. This interpretation is consistent with the process by which CPSC notifies firms when it initiates an investigation into suspected defects or hazards. In this case, we can interpret the subsequent increase in the probability of trade between the affected parties to represent a partial restoration of trust, possibly following a change in the product design, communication or quality control, or suppliers' parts subcontractors.

Next, we examine whether the lower likelihood of trade with the implicated supplier is specific to the product being recalled. Figure 5 shows the coefficient vector $\boldsymbol{\beta}$, along with $95 \%$ confidence intervals, using a different dependent variable: $\mathbb{I}\left(\operatorname{Imports}_{b s,-p, t}>0\right)$, an indicator that equals 1 iff buyer $b$ trades any other product with supplier $s$ in quarter $t$. Although the pattern of coefficients is somewhat muted, the general pattern is similar - a five percentage point dip in the probability of trade a few quarters before the public announcement. The fact that firms appear to reevaluate their entire relationship suggests that they believe the problem is not simply a random bad batch, but something more systematic, such as quality control at the producing plant. This result is consistent with the notion that buyers learn about a supplier's quality from a recall. An alternative interpretation is that buyers face economies of scope in purchasing multiple goods from a single supplier, so when they stop purchasing one product due to a recall, they may no longer view that supplier as optimal for other products.

Finally, we replace the dependent variable with $\ln \left(\operatorname{Imports}_{b s t}\right)$, the log value of imports 
by buyer $b$ from supplier $s$ in quarter $t$, capturing the intensive margin of adjustment. This variable is defined only for firms that have nonzero imports with that supplier in that quarter, so the sample is not a balanced panel. ${ }^{15}$ Figure 6 shows results for log value of trades. None of the coefficients are statistically significant, but we do observe a declining pattern in the value traded between pairs two quarters prior to the recall announcement and a recovery to levels prior to the recall a quarter after the announcement. For a relationship with a quarterly value of trade of $\$ 10$ million, this drop represents an economically large decline of about $\$ 1$ million. ${ }^{16}$

\subsection{Spillover Effects on Other Suppliers}

To study the U.S. buyer's relationships with suppliers that are not implicated by the recall, we focus on the intensive margin. We do this because the vast majority of the buyers in our sample have at least one other supplier in every quarter. ${ }^{17}$

In Figure 7, we examine how the dependent variable, $\ln \left(\operatorname{Imports}_{b,-s, t}\right)$, the log value of imports by buyer $b$ from suppliers other than $s$ in quarter $t$, changes over the 16 quarters surrounding the recall announcement. We see some evidence of diverging trends between the treated and control observations in quarters $[-8,-5]$ : U.S. buyers about to experience a recall increase their purchases from other suppliers two years before the recall announcement. The early divergence reflects the fact that we do not use the buyer's relationship with other suppliers in our control-selection procedure. However, we note that it declines so that the coefficients in quarters -3 and -2 are not statistically different from zero. In the quarter just before the recall announcement, however, there is a large and discrete jump in the value

\footnotetext{
${ }^{15}$ An alternative to log value, increasingly popular, is the inverse hyperbolic sine (IHS) of value. This variable has the advantage that it behaves much like the natural logarithm for nonzero values, but is still defined value for zero values; in both senses it is similar to $\ln (x+1)$. However, in cases like ours, in which a large share of the observations are zero, regression results using IHS of value are dominated by the extensive margin and do not shed additional light on the intensive margin.

${ }^{16}$ This is a rough approximation of the mean value of trade for a buyer-supplier pair in our sample.

${ }^{17}$ As indicated in Appendix Table A-1, the implicated supplier accounts for just $10-12 \%$ of the average buyer's overall imports.
} 
of the buyer's trade from other suppliers, of about 10\%. This value stabilizes at the new higher value for a few quarters, then continues to drift up. Although we cannot be sure that the effect in quarters $[5,7]$ is due to the recall - it may be a continuation of the drift that started two years before the recall announcement - the timing of the increase strongly suggests that it is due to the (anticipated) recall announcement and the (recent) information shock. The buyer, having dramatically reduced its reliance on the supplier of the recalled product, intensifies its reliance on other, un-implicated, suppliers.

This result, combined with those in the previous section, suggests that buyers find it relatively easy to identify and purchase from alternate suppliers when they discover a problem with an existing supplier. This may be because consumer goods, such as clothing and toys, are less reliant than some specialized intermediate goods on relationship-specific investments.

Taken together, the results also permit us to rule out a possible explanation for the abrupt decline in trade in the six months prior to the recall announcement: facing a recall, the buyer anticipates a decrease in demand for its products, and curtails orders to avoid having excess inventory. Instead, it appears that the buyer's overall demand is unaffected; only the sourcing of the product changes.

\subsection{Robustness}

In this section we explore the robustness of our results to a set of alternate control groups. To conserve space, we report these coefficients in a table format.

First, we repeat the analysis of Figure 4 using an alternative control group. This second control group addresses two possible concerns with our main analysis. First, control firms differ from treated firms in some dimensions: for example, Table 2 shows that control relationships have a larger average value of trade, as well as wider dispersion, than treated relationships. The firms may also differ in unobservable dimensions. In addition, although we are reasonably confident that we have removed relationships that may be indirectly impacted by the recall from our set of control observations, widespread concern about product 
quality from a particular country could still contaminate our results (Freedman, Kearney, and Lederman, 2012). Our alternative control group addresses the first concern by using control shipments from the same firms as the treated shipments. To avoid indirect effects, the control shipments we select occur two years prior to the treated shipments. Specifically, we use imported shipments by the recalled shipment's buyer, two years prior to the recalled shipment, from a different supplier but from the same country and in the same broad product category (HS2). We then compare the time series of the treated firm's relationship with the supplier of the recalled product around the time of the recall announcement to the relationship of the same firm with a different supplier of a broadly similar product two years earlier.

These results are shown in column (1) of Table 4. By design, this analysis is based on a smaller set of firms - ones for which we can find similar shipments, of the same HS2 product from the same country, but from a different supplier, two years prior to the recalled shipment. Consequently, the confidence intervals are larger, but the general pattern remains: the probability of trade for the treated relationships falls relative to the control relationship five quarters prior to the public announcement, then partially restores after the public announcement. The magnitude of the estimated response is approximately the same as the one depicted in Figure 4.

Next, we verify that the main result from Figure 4 holds when we shift perspective to the foreign supplier's response. Column (2) in Table 4 shows the probability that the supplier trades the recalled product with the U.S. buyer. The key difference here is the selection of the control group. We start with the same set of treatment and control shipments, but we restrict the controls to those that share key characteristics of the supplier rather than the buyer. $^{18}$ We find a 6-7 percentage point drop in the probability that the foreign supplier

\footnotetext{
${ }^{18}$ The procedure for selecting control observations parallels the one in the main sample, and is outlined in Appendix A.3. Treated observations for which we do not find appropriate controls are dropped from the analysis. Consequently, the buyer and supplier samples include overlapping, but not identical, treated relationships.
} 
trades with the U.S. buyer in the two quarters immediately before the recall announcement. Coefficients remain negative for five quarters after the announcement, although, unlike in Figure 4, they are not statistically significant in the post-announcement period.

Similarly, in column (3), we find a (marginally significant) drop of 3 percentage points in the probability that the supplier sells a different product to the same U.S. buyer in the quarter just before the recall is announced; this drop is smaller and shorter lived than the one depicted, from the buyer's perspective, in Figure 5. In column (4) we also verify that the value of trade between the two firms, if they continue trading, declines just prior to the recall. This effect, though large (a reduction of eight percent in the value of trade), is not statistically significant, as in Figure 6.

Combined, these robustness checks confirm that our results are not driven by either a particular set of control or even by a particular set of treatment observations. Across specifications, we show that the probability the treated firms trade in the recalled product falls by several percentage points in the quarters immediately before the recall announcement, then partially recover following the public announcement; the probability the firms trade in other products also falls, although to a lesser extent, as does the value of trade.

\subsection{The Role of Firm Boundaries}

Firm boundaries could affect the course of a recall adjustment in several different ways. First, affiliated buyers' tighter control and better management of their supply chains may reduce the probability of product defects, and therefore recalls. Managing an affiliated supplier is less costly than managing an unaffiliated one: Atalay, Hortaçsu, Li, and Syverson (2019) estimate that keeping transactions in-house is equivalent in magnitude to the costs of reducing distance between unaffiliated firms by $40 \%$. This idea is consistent with the model of Arrow (1975) and subsequent literature that assumes that "information transmission between upstream and downstream firms may be facilitated by vertical integration" (Holmström and Roberts, 1998, p. 90). Steven, Dong, and Corsi (2014) examine recall rates using data on 
publicly traded companies from 2010-2012, and find that recalls are more common for buyers that import goods from unaffiliated suppliers than for buyers that import only from affiliated suppliers. Nevertheless, some of our recalls do involve affiliated firms.

Conditional on experiencing a product defect leading to a recall, affiliated firms may be able to stop production and address problems sooner than unaffiliated firm. This could be because affiliated firms discover the problem sooner (possibly before being notified by CPSC of an investigation) or because they are not bound by inflexible contract terms that may characterize unaffiliated relationships.

To explore these hypotheses, we estimate the event-study regression from Figure 4 separately by the affiliation status of the relationship impacted by the recall. The treated sample contains approximately 80 affiliated and 400 unaffiliated buyer firms. ${ }^{19}$ The results are depicted in Figure 8. The coefficients for affiliated relationships are shown as hollow circles connected by a solid line; unaffiliated relationships are shown as solid circles connected by a dashed line. Both affiliated and unaffiliated relationships experience a sharp decline in the probability of trading the recalled product prior to the recall announcement, but affiliated relationships display a decline in the probability of trading the recalled product beginning four quarters prior to the recall announcement. In contrast, recalls impacting unaffiliated buyersupplier relationships experience a drop in the probability of trading the recalled product only two quarters prior to the recall announcement. This result is consistent with affiliation facilitating either earlier information flows or more flexibility to stop production and address the problems as soon as the firms become aware of a problem.

Perhaps surprisingly, although affiliated firms' response starts sooner, it is neither less severe nor shorter in duration than the response of unaffiliated firms. The magnitude of the recall effect is similar for affiliated and unaffiliated firms: the probability of trading

\footnotetext{
${ }^{19}$ Unfortunately, because of these small samples, our statistical power is limited in this specification and, generally, we cannot reject equality of the coefficients for affiliated and unaffiliated relationships. For the same reason, we are unable to explore additional outcomes separately by affiliation status of relationships.
} 
declines by 10-15 percentage points for affiliated firms, on a base of about 55\%, and by approximately 10pp for unaffiliated firms, on a base of about 45\%. And the duration of affiliated firms' response is longer: trade is suppressed for four quarters for affiliated firms and for two quarters for unaffiliated firms. These findings do not support the hypothesis that affiliated buyers' close control of, and communication with, their affiliated suppliers would act to reduce the severity of a recall-induced shock.

Finally, we may also expect trading relationships to fully recover with a higher probability in affiliated relationships than unaffiliated ones. Terminating an affiliated relationship requires either selling or closing the offshore facility, whereas terminating an unaffiliated relationship is as simple as reneging on a contract or failing to place an order. However, the results show that both affiliated and unaffiliated relationships recover to within a few percentage points of their original levels in the quarter immediately following the recall announcement.

Although the statistical power of these regressions is limited, these results suggest that affiliation confers one key advantage for firms responding to a critical production shock: the ability to respond sooner and, perhaps, more decisively. However, other hypothesized advantages of affiliation - a quicker resolution or more moderate decrease in trade - are not borne out in the data.

\subsection{Supplier Reputation}

Information about product defects and supplier quality embedded in consumer-product recalls may deter other U.S. buyers to reduce their reliance on the implicated foreign suppliers. For example, Zhao (2018) and Bai, Gazze, and Wang (2019) find evidence of reputation spillovers from product defects to other firms in the same country and the adverse reputation mostly affects entrants. In this section, we examine negative reputation spillovers on the foreign supplier in the U.S. market. 
To this end, we replace the dependent variable in our regressions with an indicator for other U.S. firms purchasing the recalled HS6 product from the recalled shipment's supplier. For this analysis, we use the "supplier sample" described in Section 4.4, which matches treatment and control observations based on the suppliers' characteristics. Figure 9 shows a 2 percentage point drop in the probability that the foreign supplier trades with other U.S. buyers one quarter after the recall announcement. Although the result is not statistically significant, the timing is consistent with U.S. buyers gaining additional information about the quality of the foreign supplier from the public announcement. ${ }^{20}$

\section{Concluding Remarks}

In the absence of a Walrasian auctioneer, relationships between buyers and suppliers are the fundamental building blocks of trade. Firms make relationship-specific investments and learn about one another over time. In this paper, we study the repercussions of a negative information shock, whereby a buyer learns about a defect in the product it had purchased from a specific supplier. Product recalls, caused by the discovery of a defect in production, represent large unanticipated shocks to individual trading relationships.

We construct a novel dataset of the universe of consumer-product recalls sourced internationally between 1995 and 2013, linked to confidential customs transactions records. Using the newly constructed linked data, we find both a short-run response and a long-run response. Compared to a control group, there is a steep decrease in the trade between the buyer and supplier in the short run, then a more muted, permanent, decrease in trade. Although the defect affects only one product, the trade relationship in other products suffers as well, consistent with the buyer having learned new information about the quality of the

\footnotetext{
${ }^{20}$ We do not estimate heterogeneous results by relationship age for two main reasons. First, the LFTTD is available beginning in 1992, so relationship age is censored, particularly in the first part of our sample. Second, firms that have long-lived relationships are also more likely to be large and to have a larger set of alternative suppliers, which makes it hard to identify the direct (i.e., partial) effect of relationship age on relationship survival.
} 
supplier or with economies of scope in purchasing. In the long run, the buyer increases its reliance on alternative suppliers of the same product.

These findings suggest that the cost of switching to other suppliers following an idiosyncratic, relationship-specific, shock is relatively low. This likely reflects our focus on consumer goods, such as clothing and toys, that are less reliant on relationship-specific investments, and are more substitutable, than intermediate goods (see, e.g., Monarch, 2018). Earlier work studying the impact of natural disasters on the relationships between buyers and their intermediate-input suppliers find an important role for input-specificity that leads to sharp declines in buyer sales in the aftermath of the disasters but which eventually recover to preshock levels. Our results highlight how firm responses differ in the presence of thick supplier markets.

We also present evidence that affiliated buyer-supplier pairs that experience a recall respond several quarters earlier than pairs that are not affiliated. This is consistent with affiliated buyers either becoming aware of issues surrounding the product defect sooner than unaffiliated buyers or being able to respond to the information faster. The result implies that the absence of firm boundaries facilitates faster information transmission and more flexible management. 
Figure 1. Recall Announcements of Imported Products, by Year

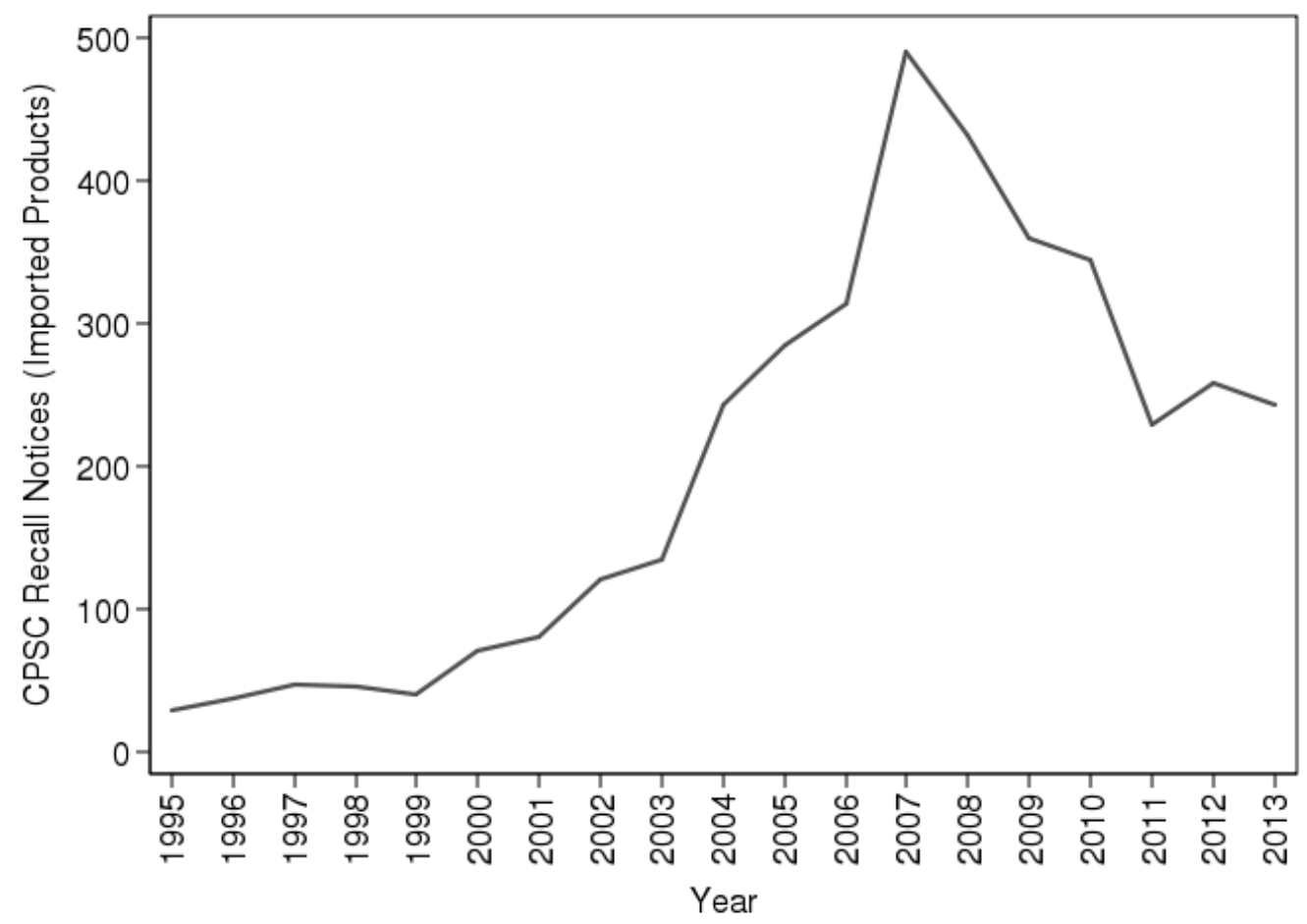

Source: Authors' calculations from CPSC data.

Figure 2. Stylized Recall Timeline

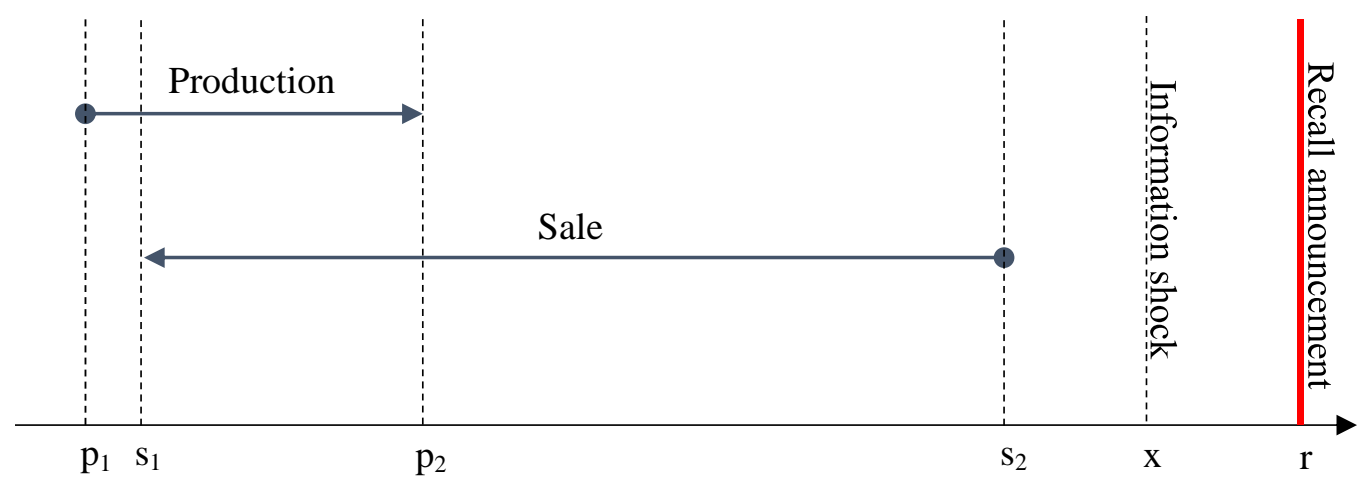




\section{Figure 3. Sample Recall Announcement}

Name of product: Toddler sweater fleece pullovers

Hazard: The snaps on the fleece pullovers can detach, posing a choking hazard.

Remedy: Refund

Recall date: September 7, 2017

Recall number: 17-766

Description: This recall involves L.L. Bean toddler sweater fleece pullovers sold in sizes 2T, 3T and 4T. The pullovers have blue trim and were sold in three colors; deep garnet (red), heather gray and light lilac. They have four snaps, two pockets and the L.L. Bean logo tag on the front. Item number 300206 and lot 02/17 are printed on woven tags in attached to the neckline of the pullovers.

Remedy: Consumers should immediately stop using the fleece pullover and contact L.L. Bean for a full refund. L.L. Bean is contacting its customers directly.

Incidents/Injuries: None reported

Sold Exclusively At: L.L. Bean stores nationwide, L.L. Bean catalog and online at www.llbean.com from April 2017 through August 2017 for about $\$ 50$.

Manufacturer(s): Century Miracle Apparel Manufacturing Co. Ltd., of Jordan

Manufactured In: Jordan

Retailer: L.L. Bean, of Freeport, Maine

Units: About 2,000

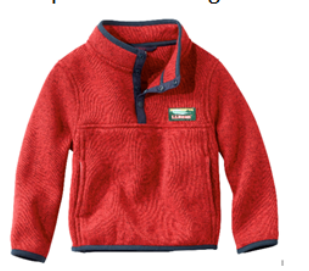

Source: https://www.cpsc.gov/Recalls/2017/L-L-Bean-Recalls-Toddler-SweaterFleece-Pullovers-Recall-Alert

Note: This recall occurred after the end of our sample period.

Figure 4. Extensive-Margin Dynamics: Buyer-Supplier-Product

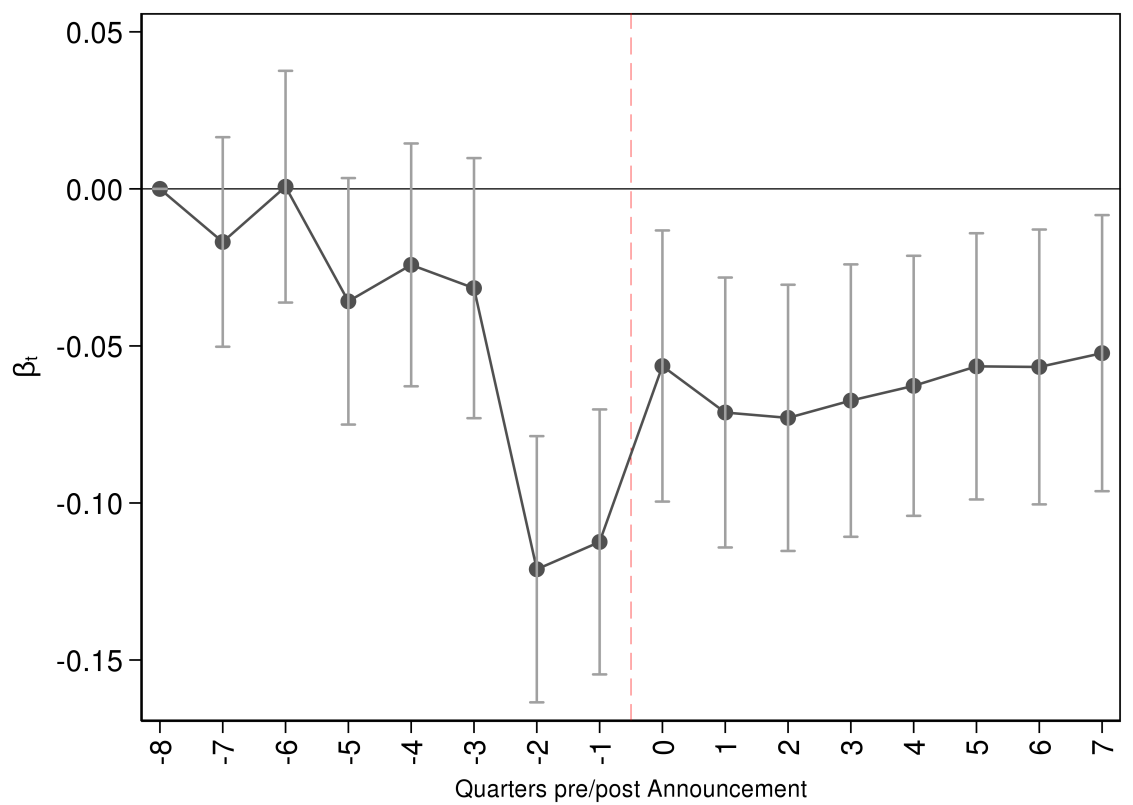

Notes: Coefficient estimates and 95\% confidence intervals showing the probability of trade between the two treated firms in the HS6 product category, for eight quarters before and after a public recall announcement, relative to control firms. The regression includes quarter and buyer-supplier-product fixed effects. 
Figure 5. Extensive-Margin Dynamics:

Buyer-Supplier-Other Product

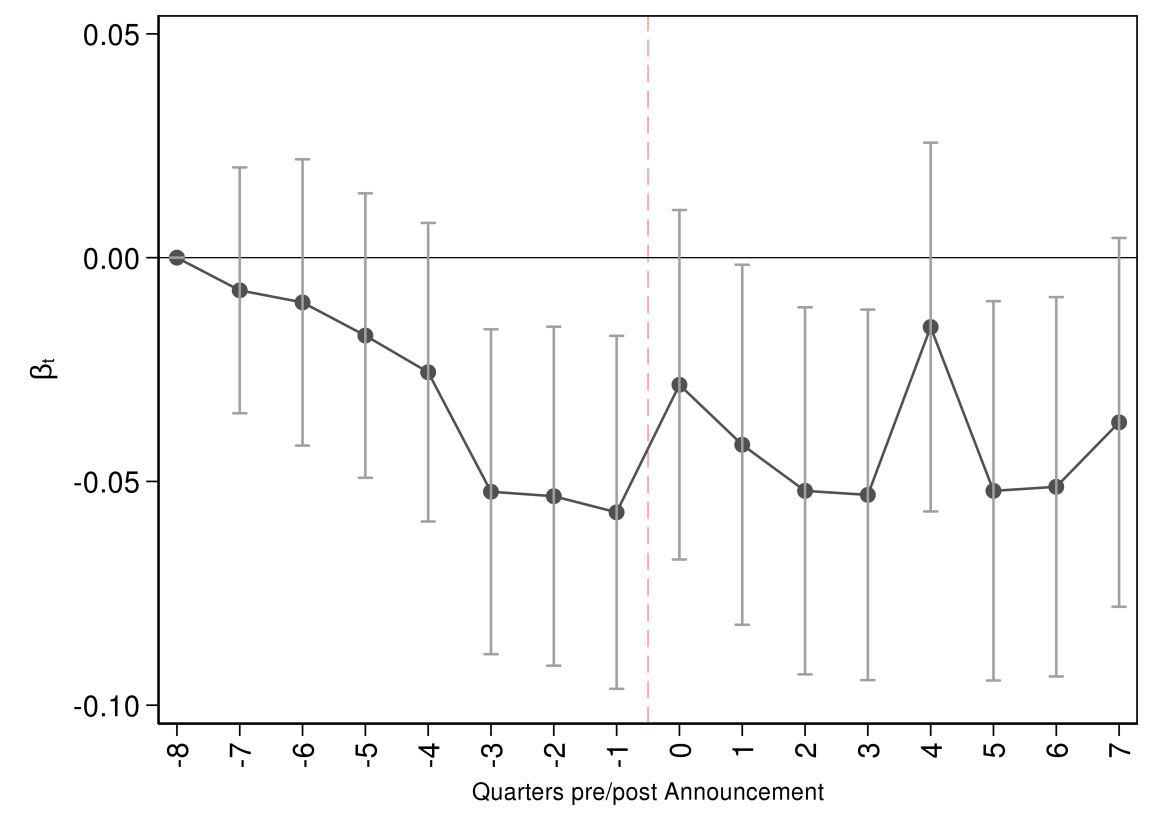

Notes: Coefficient estimates and $95 \%$ confidence intervals showing the differential probability of trade between the two treated firms in all non-recalled HS6 product categories, for eight quarters before and after a public recall announcement, relative to control firms. The regression includes quarter and buyersupplier-recalled product fixed effects. 
Figure 6. Intensive-Margin Dynamics: Buyer-Supplier

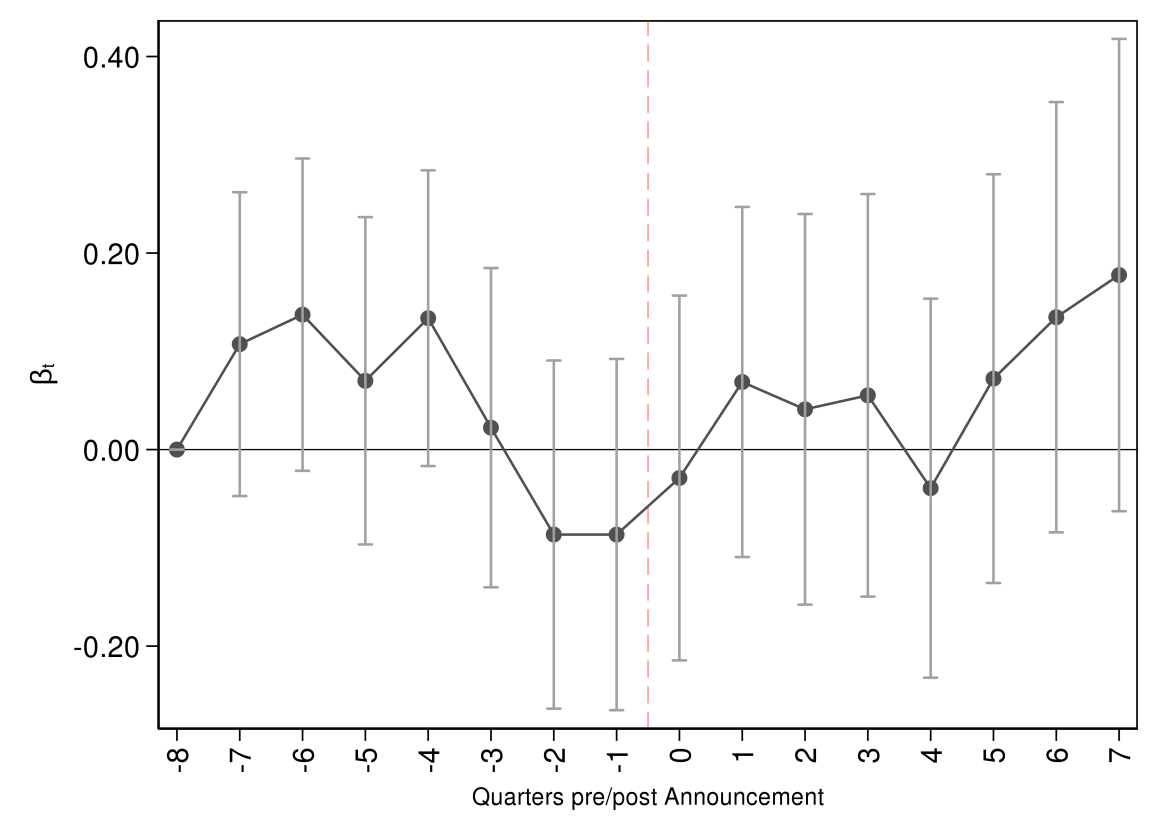

Notes: Coefficient estimates and 95\% confidence intervals showing the log value of trade between the two treated firms, conditional on having any trade in a given quarter, for eight quarters before and after a public recall announcement, relative to control firms. The regression includes quarter and buyer-by-supplier fixed effects. 
Figure 7. Intensive-Margin Dynamics: Buyer-Other Supplier

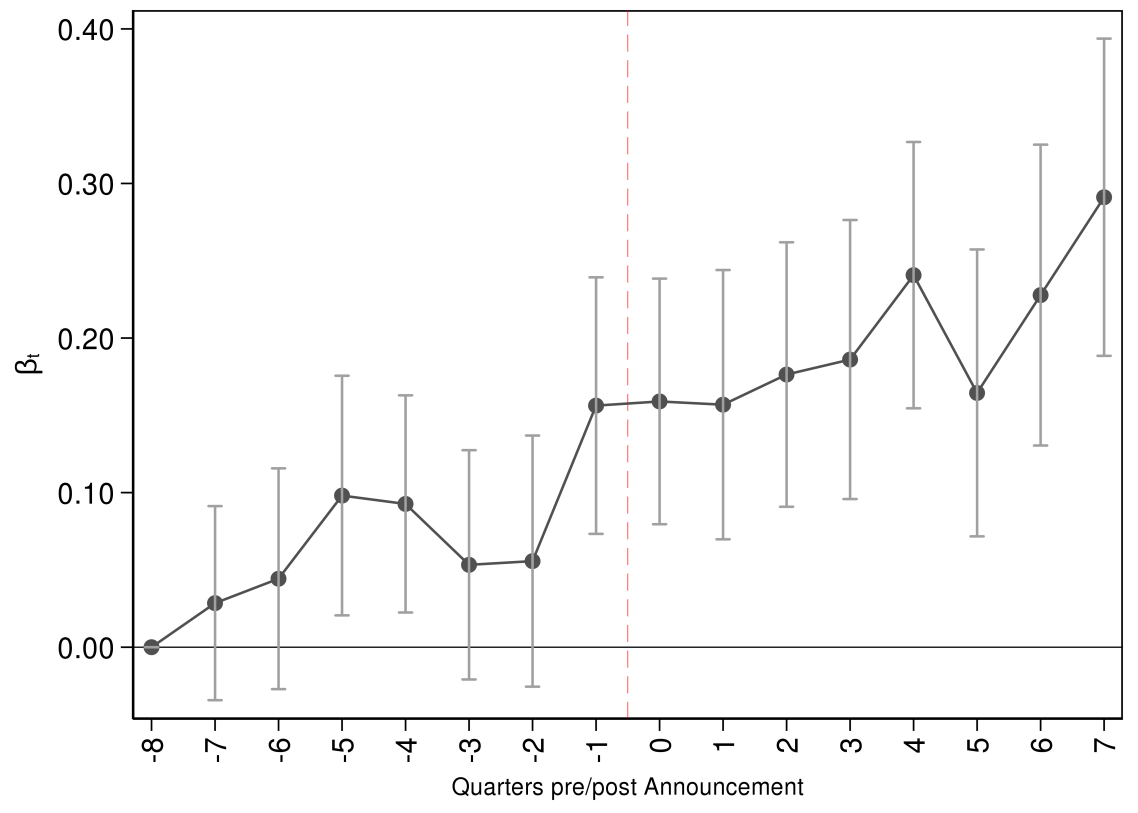

Notes: Coefficient estimates and 95\% confidence intervals showing the log value of trade between the treated U.S. buyer and all other suppliers not impacted by a recall, conditional on having any trade in a given quarter, for eight quarters before and after a public recall announcement, relative to control firms. The regression includes quarter and buyer-by-supplier fixed effects. 
Figure 8. Extensive-Margin Dynamics: Buyer-Supplier-Product by Affiliation Status

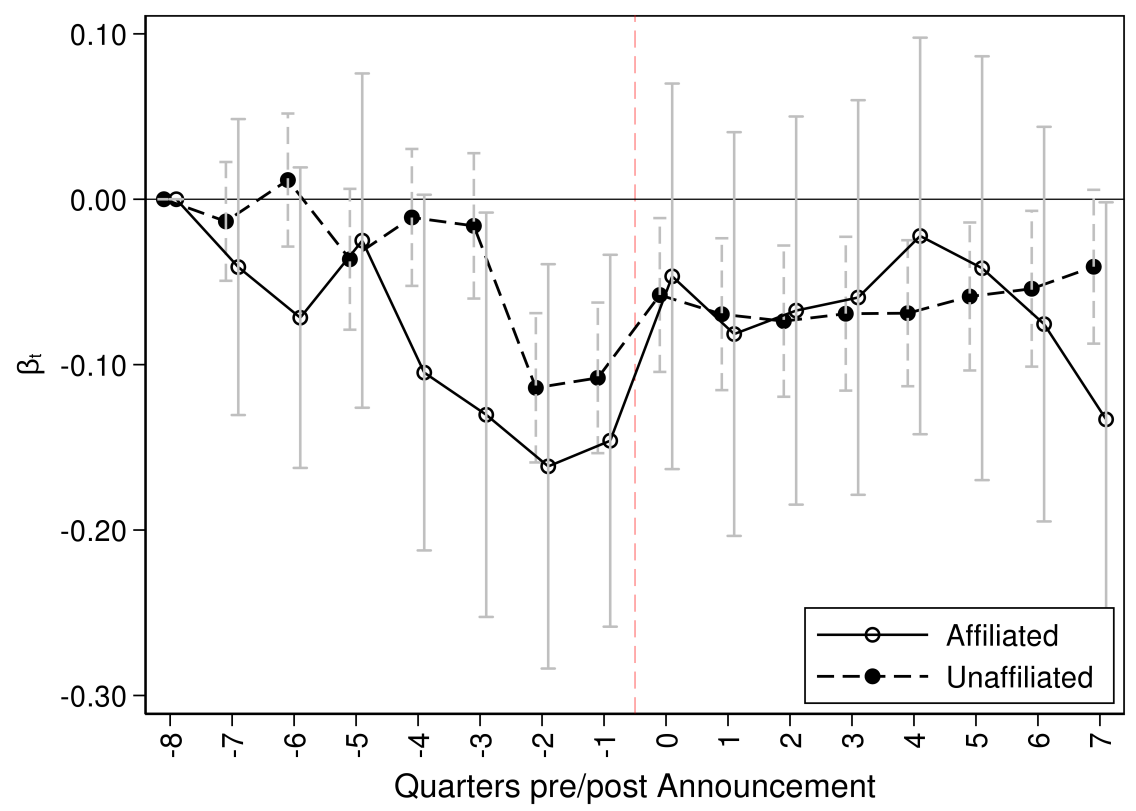

Notes: Coefficient estimates and 95\% confidence intervals showing the probability of trade between the two treated firms in the HS6 product category, for eight quarters before and after a public recall announcement, relative to control firms. Estimates for affiliated pairs and unaffiliated pairs shown separately. The buyer and seller are affiliated if the U.S. buyer owns a stake of $6 \%$ or more in the foreign supplier and vice versa. The regression includes quarter-by-affiliation and buyer-supplier-product fixed effects. 
Figure 9. Extensive-Margin Dynamics:

Supplier-Other Buyer-Product

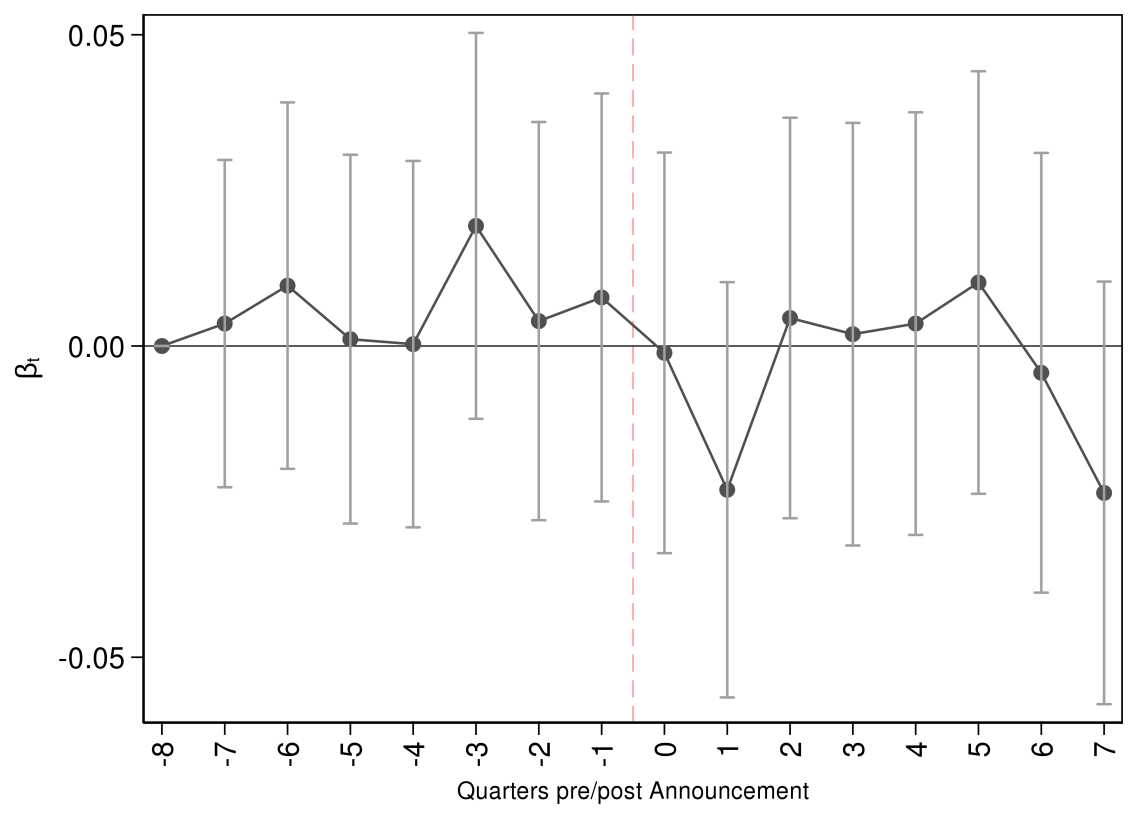

Notes: Coefficient estimates and 95\% confidence intervals showing the differential probability of trade between the treated foreign supplier and all other U.S. buyers not impacted by a recall in all recalled HS6 product categories, for eight quarters before and after a public recall announcement, relative to control firms. The regression includes quarter and buyer-supplier-product fixed effects. 
Table 1. Recalled Shipments, by HS2 Classification

\begin{tabular}{clc}
\hline HS2 & HS Description & Recalls/Shipments (\%) \\
\hline \hline 39 & Plastic and articles thereof & $0.0008738 \%$ \\
61 & Apparel, knitted or crocheted & $0.001461 \%$ \\
62 & Apparel, not knitted or crocheted & $0.0008326 \%$ \\
73 & Articles of iron and steel & $0.001101 \%$ \\
94 & Machinery and mechanical appliances & $0.0005935 \%$ \\
85 & Electrical machinery and equipment parts & $0.001178 \%$ \\
87 & Vehicles other than railway or tramway & $0.002118 \%$ \\
& Furniture, bedding, mattresses, mattress & $0.002207 \%$ \\
94 & support, cushions, lamps and lighting fittings & $0.01110 \%$ \\
\hline 95 & Toys, games, and sports requisites & $0.002385 \%$ \\
\hline All & &
\end{tabular}

Notes: Ratio of imported consumer-product recalls (from CPSC) to total imported shipments between 1995 and 2013 (from LFTTD). An import shipment is defined as a combination of a U.S. buyer-foreign supplier-HS10-date. We report statistics for the HS2 categories representing three-quarters of all imported consumer-product recalls. A product recall may be associated with multiple products. In these cases, we count a recall multiple times across product categories. Our calculation assumes that a single recall-HS2 is associated with a single import shipment.

Source: Authors' calculations from CPSC and LFTTD data. 
Table 2. Summary Statistics

\begin{tabular}{|c|c|c|}
\hline & Treatment & Control \\
\hline \multicolumn{3}{|c|}{ II(Imports HS6 product from supplier of recalled shipment) ${ }^{\mathrm{a}}$} \\
\hline Mean & $\begin{array}{c}0.4584 \\
(0.4984)\end{array}$ & $\begin{array}{c}0.4457 \\
(0.4971)\end{array}$ \\
\hline \multicolumn{3}{|c|}{$\mathbb{I}\left(\right.$ Imports other products from supplier of recalled shipment) ${ }^{\mathrm{a}}$} \\
\hline Mean & $\begin{array}{c}0.5669 \\
(0.4956)\end{array}$ & $\begin{array}{c}0.5846 \\
(0.4928)\end{array}$ \\
\hline \multicolumn{3}{|c|}{ Value of buyer's transactions with supplier ${ }^{b}$} \\
\hline Mean & $\begin{array}{c}5,776 \\
(80,310)\end{array}$ & $\begin{array}{c}14,540 \\
(250,000)\end{array}$ \\
\hline Median & 354 & 360 \\
\hline \multicolumn{3}{|c|}{ Value of buyer's transactions with other suppliers ${ }^{b}$} \\
\hline Mean & $\begin{array}{c}117,100 \\
(429,100)\end{array}$ & $\begin{array}{c}66,530 \\
(186,400)\end{array}$ \\
\hline Median & 7,534 & 7,321 \\
\hline \multicolumn{3}{|c|}{$\begin{array}{l}\text { Notes: Mean, with standard deviation in parentheses, for selected variables } \\
\text { in quarters }\{-8,-7,-6,-5\} \text { relative to the recall announcement, for both } \\
\text { treatment and control groups. For variables with highly skewed distributions } \\
\text { we also report medians. Medians are approximate, to comply with Census } \\
\text { Bureau rules on disclosure avoidance: they show the average of the values for } \\
\text { firms between the } 45 \text { th and } 55 \text { th percentiles of the variable's values. } \\
\text { a Average probability, across four quarters, that the buyer of the recalled } \\
\text { shipment purchases a product with the same HS6 (in second panel, other } \\
\text { HS6) as the recalled shipment from the seller of the recalled shipment. For } \\
\text { controls, this is the probability that the buyer of the control shipment pur- } \\
\text { chases a product with the same HS6 as the control shipment from the seller } \\
\text { of the recalled shipment. } \\
\text { b Thousands of } 2015 \text { dollars, averaged across four quarters. }\end{array}$} \\
\hline
\end{tabular}


Table 3. Summary Statistics, by Affiliation Status

\begin{tabular}{|c|c|c|c|c|}
\hline & \multicolumn{2}{|c|}{ Affiliated } & \multicolumn{2}{|c|}{ Unaffiliated } \\
\hline & Treatment & Control & Treatment & Control \\
\hline \multicolumn{5}{|c|}{$\mathbb{I}$ (Imports HS6 product from supplier of recalled shipment) } \\
\hline Mean & 0.5446 & 0.4924 & 0.4454 & 0.4396 \\
\hline & $(0.4986)$ & $(0.5001)$ & $(0.4971)$ & $(0.4964)$ \\
\hline
\end{tabular}

Notes: Mean, with standard deviation in parentheses, for selected variables in quarters $\{-8,-7,-6,-5\}$ relative to the recall announcement, for both treatment and control groups. For variables with highly skewed distributions we also report medians. Medians are approximate, to comply with Census Bureau rules on disclosure avoidance: they show the average of the values for firms between the 45 th and 55 th percentiles of the variable's values.

a Average probability, across four quarters, that the buyer of the recalled shipment purchases a product with the same HS6 (or other HS6) as the recalled shipment from the seller of the recalled shipment. For controls, this is the probability that the buyer of the control shipment purchases a product with the same HS6 as the control shipment from the seller of the recalled shipment.

b Thousands of 2015 dollars, averaged across four quarters. 
Table 4. Robustness, Alternate Control Groups

\begin{tabular}{|c|c|c|c|c|}
\hline & \multirow{2}{*}{$\begin{array}{c}\text { Alternative } \\
\text { Buyer Sample } \\
\text { Recalled Product }\end{array}$} & \multicolumn{3}{|c|}{ Supplier Sample } \\
\hline & & Recalled Product & Other Product & Log Value \\
\hline \multirow[t]{2}{*}{ Treated $\times Q_{-7}$} & 0.0315 & -0.0043 & -0.0162 & 0.0621 \\
\hline & $(0.0416)$ & $(0.0157)$ & $(0.0123)$ & $(0.0681)$ \\
\hline \multirow{2}{*}{ Treated $\times \mathrm{Q}_{-6}$} & -0.0503 & $0.0313^{*}$ & -0.0137 & 0.0770 \\
\hline & $(0.0528)$ & $(0.0179)$ & $(0.0152)$ & $(0.0721)$ \\
\hline \multirow{2}{*}{ Treated $\times Q_{-5}$} & $-0.1233^{* *}$ & -0.0061 & 0.0007 & 0.0811 \\
\hline & $(0.0566)$ & $(0.0184)$ & $(0.0152)$ & $(0.0717)$ \\
\hline \multirow[t]{2}{*}{ Treated $\times Q_{-4}$} & -0.0564 & -0.0119 & -0.0062 & 0.1104 \\
\hline & $(0.0584)$ & $(0.0186)$ & $(0.0159)$ & $(0.0696)$ \\
\hline \multirow{2}{*}{ Treated $\times \mathrm{Q}_{-3}$} & -0.0450 & -0.0260 & -0.0159 & -0.0451 \\
\hline & $(0.0664)$ & $(0.0195)$ & $(0.0166)$ & $(0.0756)$ \\
\hline \multirow[t]{2}{*}{ Treated $\times Q_{-2}$} & -0.0906 & $-0.0593^{* * *}$ & -0.0079 & -0.0518 \\
\hline & $(0.0685)$ & $(0.0196)$ & $(0.0169)$ & $(0.0814)$ \\
\hline \multirow{2}{*}{ Treated $\times \mathrm{Q}_{-1}$} & $-0.1382^{* *}$ & $-0.0690^{* * *}$ & $-0.0300^{*}$ & -0.0777 \\
\hline & $(0.0687)$ & $(0.0208)$ & $(0.0180)$ & $(0.0820)$ \\
\hline \multirow[t]{2}{*}{ Treated $\times \mathrm{Q}_{0}$} & $-0.1269^{*}$ & -0.0289 & 0.0069 & 0.0475 \\
\hline & $(0.0679)$ & $(0.0205)$ & $(0.0183)$ & $(0.0857)$ \\
\hline \multirow[t]{2}{*}{ Treated $\times \mathrm{Q}_{1}$} & $-0.1241^{*}$ & -0.0237 & -0.0162 & 0.0934 \\
\hline & $(0.0663)$ & $(0.0211)$ & $(0.0189)$ & $(0.0869)$ \\
\hline \multirow[t]{2}{*}{ Treated $\times \mathrm{Q}_{2}$} & -0.0906 & -0.0322 & -0.0100 & 0.0764 \\
\hline & $(0.0699)$ & $(0.0200)$ & $(0.0191)$ & $(0.0915)$ \\
\hline \multirow[t]{2}{*}{ Treated $\times \mathrm{Q}_{3}$} & -0.0662 & -0.0155 & -0.0084 & 0.1524 \\
\hline & $(0.0694)$ & $(0.0213)$ & $(0.0190)$ & $(0.0953)$ \\
\hline \multirow[t]{2}{*}{ Treated $\times \mathrm{Q}_{4}$} & -0.0914 & -0.0259 & 0.0102 & 0.0413 \\
\hline & $(0.0672)$ & $(0.0202)$ & $(0.0192)$ & $(0.0952)$ \\
\hline \multirow[t]{2}{*}{ Treated $\times Q_{5}$} & -0.0854 & -0.0175 & -0.0061 & 0.1196 \\
\hline & $(0.0740)$ & $(0.0207)$ & $(0.0199)$ & $(0.0967)$ \\
\hline \multirow[t]{2}{*}{ Treated $\times \mathrm{Q}_{6}$} & -0.0570 & 0.0018 & -0.0067 & 0.0683 \\
\hline & $(0.0693)$ & $(0.0207)$ & $(0.0198)$ & $(0.1021)$ \\
\hline \multirow[t]{2}{*}{ Treated $\times Q_{7}$} & -0.0580 & 0.0125 & 0.0043 & 0.1360 \\
\hline & $(0.0694)$ & $(0.0207)$ & $(0.0191)$ & $(0.1077)$ \\
\hline Observations $^{\mathrm{a}}$ & 101,000 & 104,000 & 104,000 & 50,500 \\
\hline
\end{tabular}

Notes: Coefficients on the interaction of treatment and quarterly indicators. The dependent variable in column (1) is the probability of the U.S. buyer importing the recalled product from the recalled shipment's supplier, using an alternative control group: the same buyer's relationship with a different supplier two years prior to the recall window. Dependent variables in columns (2) through (4) are, respectively: the probability of the supplier exporting the one or more shipments with the same HS6 as the recalled product to the buyer of the recalled product in a given quarter, supplying the same buyer with any other product, and the log of the supplier's value of exports to the buyer.

Robust standard errors in parentheses, clustered by recall. ${ }^{*} \mathrm{p}<10 \%$; $* * \mathrm{p}<5 \%$; *** $\mathrm{p}<1 \%$. All regressions include quarter and buyer-supplier fixed effects. Treated $\times \mathrm{Q}_{t}$ refers to the period $t$ quarter after the recall announcement. Quarter $(t=-8)$ is omitted.

${ }^{a}$ Observation counts rounded to comply with Census Bureau disclosure-avoidance rules. 


\section{A Data Appendix}

\section{A.1 Identifying Recalled Shipment}

We use the product name and detailed description to attach one or more possible HS10 codes to the recall. We assign multiple possible HS10 codes to recalls when we cannot be certain which code would have been used in the customs forms. For example, apparel items have different HS codes depending on the material (cotton vs. synthetic fibers) from which they are constructed, and this information is not always available in the recall description. As another example, musical instruments are classified under HS code 9205, but toys are classified under HS code 9503; we cannot always tell whether a "toy drum set" or "toy xylophone" is classified as a toy or as a musical instrument. As a final example, some recalls are of bundled products, such as candles and candle-holders, which may have been assigned separate HS codes at entry. ${ }^{21}$ More than half of the HS codes we assign to recalls fall into four two-digit HS codes: HS 95 (toys, games, and sports equipment); HS 85 (electrical machinery and equipment); HS 61 (articles of apparel and clothing, knitted or crocheted); and HS 94 (miscellaneous manufactured articles; primarily miscellaneous furniture items and mattresses). ${ }^{22}$

To construct a manufacturer identifier, equivalent to the MID in the LFTTD, we create an abbreviated supplier firm name by concatenating the first three letters of the first word with the first three letters of the second word in the name. Following the instructions on the Customs form for reporting MIDs (Form-7501), in cases where the supplier has a one-word name or where the second word of a supplier's name is fairly generic, like "Industries" or

\footnotetext{
${ }^{21}$ Whenever possible, we rely on a list of HS codes provided by the CPSC under the "eFiling Alpha Pilot" to assign HS codes to recalled products. This project is intended to increase CPSC's import targeting capabilities. See https://www.cpsc.gov/Imports.

${ }^{22}$ An example of a HS4 code is 6106 , "Women's or girls' blouses and shirts, knitted or crocheted." Within this HS4 code, HS 6106.20 is "[...] of man-made fibers," and HS10 code 6106.20.10.10 is the most specific: "Women's blouses and shirts, knitted or crocheted, of man-made fibers, containing $23 \%$ or more by weight of wool or fine animal hair."
} 
"Corporation," or simply repeats the name of the country, we use the first three letters of the first word only.

The recall announcement includes information about the range of dates during which the product was sold (more than 95\% of cases) and/or produced (under $5 \%$ ). Dates ranges can be exact (e.g., "from January 1 to January 31, 1999"), or vague (e.g., "spring of 1999"). In the latter case, we translate them into calendar dates, being as broad as possible.

For the press release associated with the recall depicted in Figure 3, we would extract the following information:

- Announcement date: September 7, 2017

- U.S. buyer: L.L. Bean

- MID: CENMIR

- Country: Jordan

- HS code(s): $6110,6111^{23}$

- Sale date(s): April 2017 to August 2017

- Production date(s): n/a

Our first step is to link the product recall data to the LFTTD in order to identify the shipment associated with the recall at the buyer-supplier-country-product-date level. We begin by searching the BR for firms with names identical or similar to the U.S. buyers listed in the recall announcements. ${ }^{24}$ We match $90 \%$ of the names associated with a recall to the BR. For the subset of firms identified as possible matches, we search the LFTTD to determine whether they have ever imported any products with one or more of the identified

\footnotetext{
${ }^{23}$ HS 6110 is "Sweaters, pullovers, sweatshirts, waistcoats (vests) and similar articles, knitted or crocheted;" 6111 is "Babies' garments and clothing accessories, knitted or crocheted." As this is a toddler's vest, we cannot be certain whether the adult or baby HS code was used.

${ }^{24}$ In addition to deterministic matches we allow probabilistic matching using SAS DQMATCH with a sensitivity of 95. DQMATCH is a fuzzy matching tool that recognizes strings that match inexactly but actually represent the same firm name in the context of our study. The DQMATCH function creates match codes for strings based on their characters, position, and sensitivity. See Taylor and Branum-Martin (2014) for details.
} 
HS codes from the country from which the recalled product was imported, and/or whether they have ever transacted with a firm with an abbreviated supplier name similar or identical to the abbreviated supplier name identified in the announcement, at some point before the recall-announcement date.

We limit our attention to shipments that occurred on or after the first production date, if provided in the recall announcement, and no earlier than 365 days prior to the first sale date, if no production date is available. We further limit ourselves to shipments that occurred no later than the last sale date, which is usually provided in the announcement. In rare cases the recall announcement includes information about import dates; in those cases, we limit attention to shipments in that window. For illustration purposes, consider again the stylized case depicted in Figure 2. The announcement takes place at time $r$, so we know the recalled shipment had to have occurred before $r$. The product was sold during the interval $\left[s_{1}, s_{2}\right]$, so the shipment had to have occurred before $s_{2}$. If the recall announcement includes a range $\left[p_{1}, p_{2}\right]$ for production, we can also infer that the recalled shipment had to have occurred after $p_{1}$.

Both the HS and MID matches are subject to type-I and type-II errors. The HS codes we assign to products are based on our reading of the product description and may not match with the HS code assigned by the buyer. Some products, such as toys, are relatively straightforward to assign (all toys have HS4 of 9503). Other products' HS codes depend on the exact material (such as the type of metal or the blend of a fabric), which we do not necessarily observe. We may therefore assign an incorrect HS code, which can result in incorrect matching. The manufacturer identified in the recall notice may or may not be the same as the supplying firm from which the importer purchased the product. Moreover, some press releases do not list manufacturers at all. We attempt to balance these two types of errors: when we find a close match on HS code, we allow the MID to be different in the recall data and LFTTD, and vice versa. 
Even after applying these restrictions, some recall announcements match to many different possible buyer-supplier pairs, whereas others match to just one (or in some cases, none). We limit our analysis to recalls where we identify the buyer and supplier with no more than ten possible buyer-supplier-country-HS10 matches. In some cases, we may identify a single buyer-supplier pair, but several candidate HS10s; in other cases, we may identify one or two buyers and a single HS10, but several possible suppliers. In our regressions, we limit the samples to cases where we have no more than two candidate matches on the variable of interest. For example, when we study buyer-supplier pairs, we limit ourselves to cases in which there are no more than two candidate buyer-supplier pairs; when we study buyersupplier-product tuples, we limit ourselves to cases in which the buyer, supplier and product are well identified.

In addition to the matching errors described above, MIDs may also be subject to clerical errors. Importantly, we assume that these errors are unrelated to recall events. Errors may occur due to variations in the name and address information reported on customs forms, for example, if a single supplier's MID is constructed sometimes using its full name (e.g., BaskerKamal Enterprises) and elsewhere using an abbreviated name (e.g., BKE), or if the same foreign name is transliterated in multiple ways. Such MID variations may cause attenuation bias in some of our analyses. If a single buyer always uses the same MID to refer to a single supplier, the buyer-supplier level regressions may not be impacted, but the results on the impact on other buyers of the same supplier may be attenuated. Having hand checked the list of MIDs, we believe MIDs by and large represent unique foreign firms.

\section{A.2 Identifying Control Shipments}

There are hundreds of millions of shipments in the LFTTD. We implement the following two-stage procedure to find plausible control shipments for each of the identified recalled shipments: first, we identify possible controls at the shipment level; second, we restrict the set of controls based on shared firm characteristics. 
We start by identifying one or more possible control shipments' for each recalled shipment. Control shipments must meet the following criteria: they were shipped within a 90-day window on either side of the recalled shipment, but before the recall announcement date; the country of origin is the same as for the recalled shipment; the product is the same at the HS4 level but has a different HS6. We further restrict control shipments to ensure that neither the U.S. buyer nor the foreign supplier in the control pair is part of our treatment group at any time; the foreign supplier has never traded with the buyer of the recalled (treated) shipment; and the U.S. buyer has never traded with the supplier of the recalled shipment.

These control shipments have the advantage that the control buyers and suppliers are not directly impacted by the recall, and that idiosyncratic effects associated with unobservable country, HS4, and time-period characteristics are identical in the treatment and control shipments. In particular, the control shipments share the treated shipments" industry, global and country-specific conditions, and the country's trade and exchange-rate policies.

Restricting the controls so that they do not share an HS6 or ever trade with the recalled shipment's supplier or buyer is intended to mitigate the concern that controls may be indirectly impacted by the recalls. The recall concerns a product supplied by supplier $s$ to buyer $b$; the control relationships involve two completely different firms, supplier $s^{\prime}$ and buyer $b^{\prime}$. Therefore, indirect effects due to trade diversion are extremely unlikely. Indirect effects due to reputational spillovers also seem unlikely for several reasons. First, control shipments and treated shipments share an HS4 designation, but this is a fairly broad category. For example, all toys - from dolls to train sets to balls - share a single HS4 code, but the reputation of a producer of dolls is unlikely to be sullied by a recall of train sets. Second, many of the control buyer-supplier relationships are longstanding; for these relationships, the buyer is likely sufficiently well informed about the supplier's quality that a recall of a similar product produced by a different supplier is unlikely to change its purchasing behavior.

Because the identity of the U.S. buyers is different, there is a risk that differences in 
outcomes are driven by differences in buyer-level characteristics. To address this concern, we restrict buyers in the control set to match the buyer of the treatment shipment on several characteristics: (i) affiliation status (exact match); (ii) total value of the buyer's imports in the three years prior to the recall announcement (window match); (iii) value of buyer's imports from the supplier in the three years prior to the recall announcement (window match); (iv) supplier's share of the buyer's total imports in the three years prior to the recall announcement (window match); (v) product share of buyer-supplier trade in the three years prior to the recall announcement (window match).

For affiliation status, we match recalls involving affiliated buyer-supplier pairs to control shipments by other affiliated buyer-supplier pairs, and recalls involving unaffiliated buyersupplier pairs to control shipments by other unaffiliated buyer-supplier pairs.

To match on total value of trade and value of buyer-supplier trade, we bin trade values into eight bins: less than $\$ 10,000$, between $\$ 10,000$ and $\$ 100,000$, and so on, with the largest bin capturing firms with more than $\$ 10$ billion in trade. To match on the shares (supplier as a share of buyer's total imports, and product as a share of the buyer-supplier trade), we match within 20 percentage points. If we retain more than ten control shipments for any treated shipment after making the above restrictions, we apply a 10-percentage-point cutoff instead.

Finally, if we have more than ten control shipments for a given treated shipment after applying all of the above restrictions, we restrict the control shipments to the ten closest in date to the recalled shipment's date.

Table A-1 shows some supplementary summary statistics for the treatment and control observations. The first two panels show that the treated (control) supplier, on average, accounts for about $12 \%(10 \%)$ of the treated (control) U.S. buyer's overall imports and $30 \%$ ( $22 \%$ ) of the buyer's imports of the recalled (control) product's HS6. In the third panel, we calculate the quarterly number of suppliers that the U.S. buyer trades with in the pre-recall period. The averages are 423 in the treated group and 407 in the control group, and the 
medians are 32 and 34, respectively. For the recalled product's HS6, the number of suppliers in any given pre-recall quarter is 7; the equivalent for the control group is 8 . The medians are 2 and 3 in the treated and control groups, respectively.

\section{A.3 Alternative Controls}

We use two alternative control groups in robustness checks.

The first selects controls using the same strategy outlined above, but matches the characteristics of the foreign suppliers rather than the U.S. buyers. In other words, after selecting control shipments, we narrow down the set of control relationships to match: (i) affiliation status (exact match); (ii) total value of the supplier's exports to the U.S. in the three years prior to the recall announcement (window match); (iii) value of supplier's exports to the buyer in the three years prior to the recall announcement (window match); (iv) buyer's share of the supplier's total exports to the U.S. in the three years prior to the recall announcement (window match); and (v) product share of buyer-supplier trade in the three years prior to the recall announcement (window match).

The second alternative control group takes a different approach entirely. Here, instead of starting by finding a control shipment traded between two completely different firms, we look for a control shipment imported by the same U.S. buyer that imported the recalled shipment - but two years prior to the recalled shipment. The fact that the shipment predates the recalled shipment by two years ( \pm 90 days) means that it cannot have been impacted, directly or indirectly, by the recall. The fact that it was imported by the same U.S. buyer means that any unobserved, but time-invariant, buyer-level traits, such as the longevity of its relationships, is implicitly controlled for. We further restrict the control shipments to share an HS2 product designation with the recalled shipments and to have originated from the same country.

One problem with this alternative control sample is survivor bias. By construction, any firm that is included in this sample must survive for at least two years after its control 
shipment, because the control shipment is dated two years before the recalled shipment. To remove this bias, we further restrict the sample to firms that also have at least one shipment two years after the recalled shipment.

The main downside of this alternative approach is that only large and established firms have similar shipments both two years prior to and two years following the recalled shipment, so this sample is smaller and less representative than our main sample of the full set of firms experiencing recalls. This sample also does not allow us to control for changes in market conditions between the time of the control and treated shipments.

\section{B Predicting Recalls}

Are recalls predictable? Specifically, does having one recall signal a firm's increased propensity to experience subsequent recalls?

To address this question, we use the 2007 LFTTD and CPSC data. We chose 2007 because that is the year with the highest number of recalls in our data; even then, less than $0.01 \%$ of shipments were recalled. We limit our analysis to shipments in the nine HS2 codes with the highest number of recalls, and aggregated individual shipments to the buyer-supplier-HS10-date level. ${ }^{25}$ We estimate

$$
\text { Recall }_{b s p t}=\alpha_{p}+\delta_{c(s)}+\beta \text { PriorRecalls }_{b}+\gamma_{1} \ln \left(\text { PriorValue }_{b}\right)+\gamma_{2} \mathbb{I}\left(\text { PriorValue }_{b}>0\right)+\varepsilon_{b s p t}
$$

where Recall is the probability that a shipment from supplier $s$ to buyer $b$ of product (HS10) $p$ at time $t$ is recalled (described in more detail in the next paragraph); $\alpha_{p}$ is a product fixed effect; $\delta_{c(s)}$ is a fixed effect for the supplier's country of origin; PriorRecalls is the number of buyer b's prior recalls (1992-2006) and PriorValue is the total value of imports by buyer

\footnotetext{
${ }^{25}$ The HS2 codes are listed in Table 1 . The aggregation combines shipments that arrive at the same or different ports on the same day, from the same source firm to the same destination firm, with a single HS10 code. We cannot do this analysis with the full LFTTD for computational reasons. In the 2007 file alone, even after our restriction on HS2 codes, we have more than 13 million observations.
} 
b (1992-2006, deflated using the monthly all-products CPI). The error term is clustered at the HS10 level. The fixed effects are intended to capture the possibility that some products or countries are more prone to defects than others.

The variable Recall, capturing the probability that a shipment is recalled, is constructed as follows. If we link a single CPSC announcement to a single shipment, this variable has a value of 1 . If we identify $n$ shipments as potential match candidates - for example, shipments representing multiple HS10 codes within a single HS6, or shipments representing several different buyers or suppliers - each shipment is assigned a probability of $\frac{1}{n}$. Finally, because recalls are so rare, we multiply the probability by 100,000.

Our interest is in the coefficient $\beta$ on the number of prior recalls. However, because there may be a mechanical relationship between the number of prior recalls and the total value of prior shipments, we also include the log of the prior value of all shipments. For firms with no imports in 1992-2006, we arbitrarily set the log of the value of total shipments to zero, and add an indicator to capture the difference between firms with no prior shipments and firms with prior shipments valued at $\$ 1$.

We do not interpret the coefficients causally: prior recalls are not the cause of current recalls. Rather, our interest is in examining the degree of persistence in the propensity of firms to experience recalls. A positive coefficient $\beta$ indicates that firms that experienced a previous recall are more likely to experience another one, perhaps because of poor qualitycontrol protocols, or because they import products particularly susceptible to defects (even within the HS10 product category).

The results are shown in the first column of Table B-1. The probability that a buyer's shipment is recalled is not correlated with the probability that a prior shipment was recalled: the coefficient of 0.001 implies that each additional prior shipment that the buyer had recalled is associated with an increase of $\frac{1}{100,000,000}$ in the probability that a current shipment is recalled.

In column (2) we replace PriorRecalls ${ }_{b}$ and PriorValue Py PriorRecalls $_{s}$ and PriorValue P $_{s}$ 
the probability that a supplier's prior shipment was recalled, and the supplier's total value of prior shipments. Here the coefficient is considerably larger, but still very small in absolute value and not statistically significant. The mean probability that a shipment is recalled, from Table 1, is approximately $0.002 \%$; the coefficient of 0.095 implies that a supplier's prior recall is associated with an increase in the probability of a current recall of less than $0.0001 \%$, or one hundredth of the mean.

In column (3) we replace PriorRecalls $s_{b}$ and PriorValue Py PriorRecalls $_{b s}$ and PriorValue Prs $_{b}$ : the probability that the buyer-supplier pair had a prior recall, and the pair's prior trade value. The coefficient $\beta$ is ten times larger than in the prior column, but not statistically significant.

Finally, in column (4) we include all three prior recall counts - for the buyer, the supplier, and the buyer-supplier pair - as well as all of the prior trade values. All three coefficients are larger but none are statistically significant.

These regressions are all conditional on a future shipment to a U.S. buyer: if the supplier's reputation is sufficiently sullied, because the defect that precipitated the original recall is deemed to be a signal of its poor quality, its orders may dry up and we will not observe additional shipments in our data. In that sense the selection effect may under-estimate the true extent to which a supplier's prior recalls reflect upon its future quality.

These results demonstrate that recalls are largely unpredictable - at least, within a narrow product and country classification. Our interpretation of this finding is that treating recalls as quasi-exogenous in the main specifications in the paper is reasonable. Nevertheless, all of our specifications include buyer-supplier fixed effects to allow for the possibility that some buyers, suppliers, or buyer-supplier pairs have a higher propensity to produce defective products. As long as this propensity is time-invariant, reflecting the underlying quality of the supplier, relationship-specific fixed effects in our event-study regressions in the paper should be sufficient to control for differences between treated and control relationships. 
Table A-1. Supplementary Summary Statistics

Treatment

Control

\begin{tabular}{|c|c|c|}
\hline \multicolumn{3}{|c|}{ Supplier share of buyer's total import value ${ }^{a}$} \\
\hline Mean & $\begin{array}{c}0.1233 \\
(0.2346)\end{array}$ & $\begin{array}{c}0.1034 \\
(0.2071)\end{array}$ \\
\hline \multicolumn{3}{|c|}{ Supplier share of buyer's import value for recalled HS6 ${ }^{\mathrm{a}}$} \\
\hline Mean & $\begin{array}{c}0.3017 \\
(0.3831)\end{array}$ & $\begin{array}{c}0.2189 \\
(0.3452)\end{array}$ \\
\hline \multicolumn{3}{|c|}{ Number of suppliers ${ }^{b}$} \\
\hline Mean & $\begin{array}{r}422.7 \\
(2,656)\end{array}$ & $\begin{array}{r}406.6 \\
(3,160)\end{array}$ \\
\hline Median & 32 & 34 \\
\hline \multicolumn{3}{|c|}{ Number of suppliers of recalled $\mathrm{HS}^{\mathrm{c}}$} \\
\hline Mean & $\begin{array}{r}7.287 \\
(19.61)\end{array}$ & $\begin{array}{r}8.482 \\
(16.15)\end{array}$ \\
\hline Median & 2 & 3 \\
\hline
\end{tabular}

Notes: Mean, with standard deviation in parentheses, for selected variables in quarters $\{-8,-7,-6,-5\}$ relative to the recall announcement, for both treatment and control groups. For variables with highly skewed distributions we also report medians. Medians are approximate, to comply with Census Bureau rules on disclosure avoidance: they show the average of the values for firms between the 45th and 55th percentiles of the variable's values.

a Ratio of buyer's value of shipment (for all products or within HS6) from the supplier of the recalled shipment to the buyer's total value of shipments (for all products or within HS6). For the controls, this is the ratio of the buyer's value of shipments from the supplier of the control shipment to the buyer's total value of shipments.

b Number of suppliers with which the firm transacted, averaged across four quarters.

${ }^{c}$ Number of suppliers from which the firm purchased the recalled HS6, averaged across four quarters. For the controls, this is the number of suppliers from which the firm purchased the control shipment's HS6. 
Table B-1. Predicting Product Recalls

\begin{tabular}{lcccc}
\hline \multicolumn{4}{c}{ Probility of Recall $\times 100,000$} \\
\hline \hline & $(1)$ & $(2)$ & $(3)$ & $(4)$ \\
\hline Buyer's prior recalls & 0.001 & & & 0.005 \\
$\quad(1992-2006)$ & $(0.049)$ & & & $(0.052)$ \\
Supplier's prior recalls & & 0.095 & & 0.189 \\
$\quad(1992-2006)$ & & $(0.475)$ & & $(0.349)$ \\
Relationship's prior recalls & & & 0.947 & 1.148 \\
$\quad(1992-2006)$ & & $(1.753)$ & $(1.848)$ \\
\hline
\end{tabular}

Notes: Sample includes LFTTD shipments in 2007 aggregated to the buyer-supplier-HS10-date level. The dependent variable is 100,000 times the assigned probability that the shipment was recalled. Standard errors are clusted by HS10. Each regression has 13,410,000 observations. All regressions control for HS10 and country-of-origin fixed effects. In columns (1) and (4) we also control for the buyer's total dollar value of shipments, 1992-2006; in columns (2) and (4) we control for the seller's total value of shipments over this time period; and in columns (3) and (4) we control for the value of the pair's shipments.

* significant at $10 \%$; ** significant at 5\%; *** significant at $1 \%$ 


\section{References}

Antrás, P., T. C. Fort, and F. Tintlenot (2017) "The Margins of Global Sourcing: Theory and Evidence from U.S. Firms," American Economic Review, 107(9), 2514-2564.

Arrow, K. J. (1975) "Vertical Integration and Communication," Bell Journal of Economics, $6(1), 173-183$.

Atalay, E., A. Hortaçsu, M. J. Li, and C. Syverson (2019) "How Wide is the Firm Border?," Quarterly Journal of Economics, 134(4), 1845-1882.

Atalay, E., A. Hortaçsu, and C. Syverson (2014) "Vertical Integration and Input Flows," American Economic Review, 104(4), 1120-1148.

Bai, J., L. Gazze, and Y. Wang (2019) "Collective Reputation in Trade: Evidence from the Chinese Dairy Industry," NBER Working Paper 26283.

Barrot, J.-N., and J. Sauvagnat (2016) "Input Specificity and the Propagation of Idiosyncratic Shocks in Production Networks," Quarterly Journal of Economics, 131(3), 1-50.

Boehm, C. E., A. Flaaen, and N. Pandalai-Nayar (2019) "Input Linkages and the Transmission of Shocks: Firm-Level Evidence from the 2011 Tohoku Earthquake," Review of Economics and Statistics, 101(1), 60-75.

Consumer Reports (2018) "Takata Airbag Recall: Everything You Need to Know: What This Recall Means to You and What Actions You Should Take," Consumer Reports, October $25,2018$.

DeSalvo, B., F. Limehouse, and S. D. Klimek (2016) "Documenting the Business Register and Related Economic Business Data," U.S. Census Bureau Center for Economic Studies Working Paper 16-17.

Fort, T. C. (2017) "Technology and Production Fragmentation: Domestic versus Foreign Sourcing," Review of Economic Studies, 84(2), 650-687.

Freedman, S., M. Kearney, and M. Lederman (2012) "Product Recalls, Imperfect Information, and Spillover Effects: Lessons from the Consumer Response to the 2007 Toy Recalls," Review of Economics and Statistics, 94(2), 499-516.

Holmes, T. J. (1999) "Localization of Industry and Vertical Disintegration," Review of Economics and Statistics, 81(2), 314-325.

Holmström, B., and J. Roberts (1998) "The Boundaries of the Firm Revisited," Journal of Economic Perspectives, 12(4), 7394.

Kamal, F., and R. Monarch (2018) "Identifying Foreign Suppliers in U.S. Merchandise Import Transactions," Review of International Economics, 102(1), 128-140. 
Kumar, S., and S. Schmitz (2011) "Managing Recalls in a Consumer Product Supply Chain Root Cause Analysis and Measures to Mitigate Risks," International Journal of Production Research, 49(1), 235-253.

Lyles, M. A., B. B. Flynn, and M. T. Frohlich (2008) "All Supply Chains Don't Flow Through: Understanding Supply Chain Issues in Product Recalls," Management and Organization Review, 4(2), 167-182.

Monarch, R. (2018) “It's Not You, It's Me': Prices, Quality and Switching in U.S.-China Trade Relationships," unpublished paper, Federal Reserve Board of Governors.

Ramondo, N., V. Rappoport, and K. J. Ruhl (2016) "Intrafirm Trade and Vertical Fragmentation in U.S. Multinational Corporations," Journal of International Economics, 98, $51-59$.

Steven, A. B., Y. Dong, and T. Corsi (2014) "Global Sourcing and Quality Recalls: An Empirical Study of Outsourcing-Supplier Concentration-Product Recall Linkages," Journal of Operations Management, 32(5), 241-253.

Taylor, P., and L. Branum-Martin (2014) "Adding the Power of DataFlux® to SASß Programs Using the DQMATCH Function," SAS Global Forum Paper 1850-2014.

U.S. Consumer Product Safety Commission Office of Compliance \& Field Operations (2012) "Recall Handbook," https://www.cpsc.gov/s3fs-public/8002.pdf, accessed July 11, 2017.

Zhao, Y. (2018) "Your (Country's) Reputation Precedes You: Information Asymmetry, Externalities and the Quality of Exports," unpublished paper, George Washington University.

Zhong, J. (2018) "Reputation of Quality in International Trade: Evidence from Consumer Product Recalls," unpublished paper, University of Alberta. 